\title{
Negative priming from ignored distractors in visual selection: A review
}

\author{
ELAINE FOX \\ University of Essex, Colchester, England
}

\begin{abstract}
Ignoring a distractor on a prime trial generally impairs responses to that object on a subsequent probe trial. This negative-priming (NP) effect supports the notion that distracting objects are actively inhibited during target selection (Tipper, 1985). Alternatively, NP may be caused either by a mismatch between the features of items across prime and probe trials (Park \& Kanwisher, 1994) or by the episodic retrieval of information from the prime trial which conflicts with the current, correct response (Neill \& Valdes, 1992). These alternative accounts are called the selective inhibition, feature mismatching, and episodic retrieval hypotheses, respectively. The present paper reviews the NP literature and considers the evidence for each of the three accounts. Feature mismatching does produce NP in a limited number of cases, but it is not a necessary condition for NP. In other cases, NP must be due to either selective inhibition or episodic retrieval of previously ignored distractors. Though results from critical tests designed to discriminate among these hypotheses have not yet been reported, such results are crucial for both theoretical and practical reasons.
\end{abstract}

In the natural environment, we are frequently confronted with multiple visual objects, only a subset of which are relevant for current behavior. Thus, a central aspect of coherent perceptual-motor processes is the ability to select and respond to relevant objects and the ability to successfully ignore irrelevant objects. The nature of the mechanisms underlying this visual selective attention is of enduring interest to cognitive psychologists.

Traditional theories of visual selective attention have argued that selection of a target from a distractor is primarily an excitatory process. Attention is viewed as a single process (e.g., a beam of a spotlight), which operates on attended information (see Allport, 1989, 1993; Johnston \& Dark, 1986; Kahneman \& Treisman, 1984; Lambert, 1985; van der Heijden, 1992, for reviews of these theories). More recently, however, models of attention have been proposed that emphasize a dual process that operates oii both attended and ignored (irrelevant) information (e.g., Houghton \& Tipper, 1994; Keele \& Neill, 1978; Neill, 1977, 1989; Neumann \& DeSchepper, 1992; Tipper, 1985; Yee, 1991). The idea is that visual selection might best be achieved by the previously described excitatory mechanism, which is supplemented by an inhibitory mechanism that acts to suppress com-

Much of this work was conducted while the author was with the Department of Psychology, Victoria University, Wellington, New Zealand, and during a sabbatical period at the Laboratory of Experimental Psychology, University of Sussex, U.K. I thank John Flowers, Bill Johnston, Murray White, and three anonymous reviewers for their comments and suggestions on earlier versions of this manuscript. I am especially grateful to James Neely and Tram Neill, whose comments were particularly helpful in facilitating revision of this article. Correspondence concerning this article should be addressed to E. Fox, Department of Psychology, University of Essex, Wivenhoe Park, Colchester CO4 3SQ, U.K. (e-mail: efox@essex.ac.uk). peting information derived from analysis of irrelevant stimuli (Houghton \& Tipper, 1994). This type of model has to a large extent been prompted by the phenomenon of negative priming (NP; e.g., Tipper, 1985). NP is the demonstration that when an object is ignored, subsequent responses to that object are slower or less accurate than responses to new objects. This NP effect contrasts with the positive priming (PP) effect, which is the demonstration that attending to an object facilitates subsequent responding to that object (e.g., Scarborough, Cortese, \& Scarborough, 1977). NP from ignored objects indicates that cognitive processes operating on irrelevant information may be a critical component of visual selection. This notion has profound consequences for our theoretical understanding of attention. It is therefore important to gain a fuller understanding of such mechanisms, particularly since inhibitory processes may be critical at all stages of cognition (see Dagenbach \& Carr, 1994, for examples). The current paper provides an empirical review of the NP literature. A primary aim is to establish whether NP provides compelling evidence for the selective inhibition of distracting objects during selective attention. ${ }^{1}$

In a typical NP experiment, two trials are presented in rapid succession; the first is generally called the prime trial, and the second is called the probe trial. In both trials, the subject usually attends to one item and attempts to ignore distracting material. The critical probe trials are those in which the previously ignored distractor is presented as the to-be-responded-to target. Slowing of response in these ignored repetition trials was first discovered using Stroop tasks in which subjects named the ink color of color-word stimuli. For example, DalrympleAlford and Budayr (1966) found that the total time to name colors in a list of Stroop words was slower if each 
color corresponded to the distractor word immediately preceding it in the list (i.e., in related conditions), relative to control (unrelated) conditions. To illustrate, it took longer to respond "red" to the red stimulus green if it was preceded by the word red printed in blue than it did if it was preceded by the word yellow printed in blue. Neill (1977, Experiment 1) has since established that this distractor suppression effect occurs even when randomized, individually presented Stroop words are used (see also Lowe, 1979, 1985).

Similar results have been found with line drawings of familiar objects. For example, Tipper (1985) presented subjects with displays containing two superimposed pictures; the target picture was printed in red, while the distracting picture was printed in green. The subject's task was to remember the prime target, name the probe target as rapidly as possible, and then recall the prime target. When the distractor on the prime trial subsequently became the target on the probe trial (i.e., the ignored repetition condition), naming latencies were slower than they were when the prime and probe trials were unrelated. Subsequent research demonstrates similar NP effects in selective-attention tasks that require letter naming (e.g., Tipper \& Cranston, 1985), picture naming (e.g., Allport, Tipper, \& Chmiel, 1985; Tipper, 1985), word naming (Tipper \& Driver, 1988), letter matching (Neill, Lissner, \& Beck, 1990), lexical decisions (e.g., Yee, 1991), letter counting (Driver \& Tipper, 1989), matching of nonsense shapes (DeSchepper \& Treisman, 1991), and target localization (e.g., Tipper, Brehaut, \& Driver, 1990). Thus, NP appears to be a robust effect of broad generality, since it occurs across a range of stimuli (words, letters, pictures, numbers, and nonsense shapes), and across a variety of task demands (categorization, matching, counting, and localization).

\section{THEORETICAL ACCOUNTS OF NEGATIVE PRIMING}

The dominant view is that NP is a reflection of inhibitory mechanisms in visual selective attention (e.g., Allport et al., 1985; Fox, 1994b; Houghton \& Tipper, 1994; Milliken, Tipper, \& Weaver, 1994; Moore, 1994; Neill, 1977, 1979, 1989; Neill \& Westberry, 1987; Neumann \& DeSchepper, 1991, 1992; Tipper, 1985; Tipper \& Cranston, 1985; Tipper, Lortie, \& Baylis, 1992; Tipper, Weaver, Cameron, Brehaut, \& Bastedo, 1991; Tipper, Weaver, \& Houghton, 1994; Tipper, Weaver, Kirkpatrick, \& Lewis, 1991; Yee, 1991). This is the selective inhibition account. Two alternative accounts of NP have been proposed that make no assumption that ignored material is inhibited. The first of these concerns the possibility that attending to the probe target may lead to the automatic retrieval of information from the prime trial that conflicts with the information present in the probe display. This conflict produces an ambiguity that results in delayed processing on the probe trial (Lowe, 1979; Milliken et al., 1994; Park \& Kanwisher, 1994). This is the feature mismatching account. A related hypothesis
(Neill \& Valdes, 1992; Neill, Valdes, Terry, \& Gorfein, 1992) suggests that NP is produced by the memory retrieval of an episode in which the current target stimulus was ignored. This may create a conflict between a $d o-$ not-respond tag encoded with the ignored distractor on the prime trial, and a respond tag associated with that item when it becomes a target on the probe trial, thus producing a delay in responding on the probe trial. This is the episodic retrieval account. Each of these theoretical interpretations of NP will be briefly considered; following that, the empirical literature of NP will be reviewed.

\section{Selective Inhibition}

The selective inhibition account of NP proposes that selective attention involves two separate mechanisms. First, processing of relevant information may be facilitated or activated-termed amplification by Houghton and Tipper (1994). Second, processing of irrelevant information is initially activated, and then may be suppressed or inhibited. The inhibitory mechanism is assumed to operate on postcategorical representations of ignored items (e.g., Neumann \& DeSchepper, 1992; Tipper, 1985; Yee, 1991), so that this view is essentially an extension of traditional late-selection theory (Deutsch \& Deutsch, 1963; Duncan, 1980). More recently, it has been suggested that an inhibitory mechanism may only be implemented if the activated representations of ignored objects are associated with the current behavioral goals of the organism (Milliken et al., 1994; Tipper et al., 1994) and/or are likely to disrupt correct responding (e.g., Fox, 1994b; Moore, 1994). A formal connectionist model of inhibitory mechanisms in selective attention has recently been presented by Houghton and Tipper (1994).

In this account of NP, an important question concerns what is inhibited. Neill (1979) originally suggested that the activated mental representations of ignored items might be "deactivated" by an inhibitory mechanism. If the mental representations themselves are inhibited, they will obviously be more difficult to respond to when subsequently presented as a target. This conception, however, cannot account for the finding that ignored distractors sometimes produce $\mathrm{PP}$ on probe trials that contain no distractor, even though they produce NP on randomly intermixed probe trials that do contain a distractor (e.g., Lowe, 1979; Moore, 1994). Thus, once inhibition is removed, facilitation emerges that cannot be explained by the deactivation hypothesis. An alternative view is that the mental representation of an ignored distractor remains activated, but the links between the activated representation and the response mechanism are blocked (Tipper \& Cranston, 1985). The idea is that as long as a selection state is maintained, inhibition will continue. If, however, the selection state is dropped, PP may occur, since the distractor representation is still activated. Both of these explanations of the NP effect assume that NP is due to the selective inhibition of distracting information during the prime trial. This inhibition persists to the probe trial, thus slowing responses to information related to the ignored distractor. 


\section{Feature Mismatching}

While NP is most often attributed to distractor inhibition, it is possible that a lack of correspondence between the features of an ignored prime item and those of a subsequent probe target could by itself produce NP. To illustrate, Lowe (1979) presented a color-naming task in which the prime stimulus consisted of a color-word followed by unpredictable presentations of another colorword or by just a color-patch (i.e., not by a conflicting color-word). Significant NP was obtained when colorwords served as the probe stimulus, but RTs were facilitated when the probe was a color-patch. Lowe argued that in the related condition, in which subjects have ignored a word that names the current target (e.g., red printed in blue followed by green printed in red), the color name of the probe stimulus is doubly representedonce as an ignored distractor, and once as a selected target color. The color name is therefore highly ambiguous, and time is required to resolve this ambiguity. In the previous example, for instance, the subject responded "blue" on Trial $n$, which was associated with the identity red. In the following trial $(n+1)$, the subject is required to respond "red," which is now associated with the identity green. This mismatch elicits a further check of the stimulus before a response is released. On this view, the NP effect is due to a mismatch between the features of the ignored distractor and the features of the subsequent target.

A very similar account of the NP effect has recently been proposed by Park and Kanwisher (1994). In a spatial NP task, they reported results that suggest that NP is due to a change in the symbol identity bound to a particular location, rather than to a change in the status of that location from distractor to target (see Tipper et al., 1990). To illustrate, subjects were required to report the location of an $O$ in a prime display, while ignoring the location of an $X$. Then, in a probe display, the subjects were required to report the location of an $X$ and to ignore the location of an $O$. The critical result was that NP occurred when the symbols occupying the probe-target location changed between the prime and the probe displays, but that facilitation was found when the symbols at that location did not change (e.g., when an $X$ appeared in the same location on both prime and probe displays, $\mathrm{PP}$, rather than NP, was observed). These results are predicted by the mismatching hypothesis because it assumes that NP is produced when the probe target differs from the item that occupies its position in the prime display, independently of whether that prime item was a distractor or a target (Park \& Kanwisher). In contrast, the selective inhibition account would not predict this result, since it considers NP to be caused by the inhibition of an ignored item that subsequently becomes a target. In brief, the feature mismatching hypothesis assumes that NP is a backward-operating effect caused by a mismatch between codes on successive trials, instead of by inhibition of distractors during the prime trial that carries forward to the probe trial.

\section{Episodic Retrieval}

The third account of NP also assumes that it is caused by the implicit retrieval of information from the prime trial which conflicts with the current, correct response (Neill \& Valdes, 1992; Neill, Valdes, Terry, \& Gorfein, 1992). This account emphasizes the role of the probe stimulus as a memory-retrieval cue. The idea is that processing the probe target in an ignored repetition condition leads to an automatic retrieval of the previous processing episode (i.e., the prime display). Such instances (episodes) may contain information about the identity and/or location of items, their status as "relevant" or "irrelevant," and the response they require (respond vs. do not respond). If there is a conflict in the retrieval episode, whereby an item previously encoded as irrelevant on the prime trial is now coded as relevant on the probe trial, slower RTs occur because of the mismatch between processing episodes, not because of inhibition applied during the prime trial. To illustrate, assuming the current (probe) target, B, was an ignored distractor on the immediately preceding prime trial, the $B-d o$ not respond association stored during the prime trial interferes with the $B$-respond association on the probe trial. Thus, responses might be slowed on ignored repetition trials because the nonresponse encoded in the episodic memory trace conflicts with the appropriate response. Neill, Valdes, Terry, and Gorfein (1992) also point out that responses on ignored repetition trials may be slowed because the lack of correct response information may force subjects to rely on slower algorithmic processing to elicit the appropriate response (see Logan, 1988).

It is important to draw a distinction between Neill's episodic retrieval theory of NP (Neill \& Valdes, 1992; Neill, Valdes, Terry, \& Gorfein, 1992) and the feature mismatching theory of NP (Lowe, 1979; Park \& Kanwisher, 1994). While both accounts rely on the notion that attending to a probe stimulus induces the retrieval of a previous processing episode, the explanation of the resulting NP effect is different. On the episodic retrieval account, the probe target's previous status as a prime distractor (i.e., a previously ignored object) is necessary for NP to occur. In contrast, the feature mismatching account (e.g., Park \& Kanwisher) requires not that the current target was previously ignored, but simply that it appeared (as a target or a distractor) on a previous trial. Because of this, Milliken et al. (1994) have argued that Neill, Valdes, Terry, and Gorfein's (1992) episodic retrieval account of NP is closer to the distractor inhibition account of NP, since both models assume that the current target's previous role as an ignored distractor is the critical factor in producing NP.

\section{HOW CAN PROCESSING OF IGNORED INFORMATION BE MEASURED ?}

The foregoing overview indicates that the processing of ignored information appears to be an important component of visual selection. On the one hand, processing and 
subsequent inhibition of irrelevant information may be a critical mechanism underlying selection of target objects (Houghton \& Tipper, 1994). On the other hand, the retrieval of previous processing episodes may be an important mechanism for maintaining attention to a particular source of information over time (Neill, Valdes, Terry, \& Gorfein, 1992). For example, Tipper, Weaver, Cameron, et al. (1991) point out that in the natural environment, relevant stimuli tend to be consistently relevant, and irrelevant stimuli are likely to remain consistently irrelevant. Thus, episodic retrieval of previous processing episodes would generally allow for unhindered perception-action interactions. Only when irrelevant stimuli become relevant would a delay be apparent. Whether selective inhibition, feature mismatching, or episodic retrieval turn out to be the best explanation of NP, the phenomenon itself establishes that the identities (and locations) of ignored items are indeed encoded. Thus, the analysis of ignored information appears to be ubiquitous in information processing, and may have important functional consequences. This section briefly describes three paradigms that have been widely used to index the extent of processing of ignored information.

\section{Stroop Task}

The traditional Stroop task involves presenting subjects with lists of color-words printed in various colors (Stroop, 1935). The subject is required to respond to one dimension of the stimulus (i.e., to read the word or name the color), while ignoring the other dimension. When subjects are required to read the word, they encounter little or no interference from an incongruent ink color, but when they are required to name the color in which the word is printed, substantial interference is observed from an incongruent color-word (see MacLeod, 1991, for a review). This Stroop interference indicates that subjects cannot avoid processing an ignored word when required to name its color. It should be noted, however, that because both attributes of the Stroop stimulus (i.e., ink color and word) are part of a single object, this task cannot adequately address the issue of mandatory semantic analysis of ignored distractors (e.g., Treisman, 1969).

\section{Flanker Task}

To determine more clearly whether ignored items are automatically processed, a task is required in which the to-be-attended and the to-be-ignored items are separate objects. Early work demonstrated that Stroop-like effects do indeed occur even when the ignored color-word is spatially separate from an attended color patch (e.g., Dyer, 1971; Gatti \& Egeth, 1978). A more widely used paradigm that also meets the criterion of separate target and distractor objects is the Eriksen flanker task (Eriksen \& Eriksen, 1974). The usual procedure is that two letters (e.g., $H$ and $K$ ) are mapped to responses from one hand, and another two letters (e.g., $S$ and $C$ ) are mapped to responses from the other hand. The subjects are required to categorize a centrally presented target letter and to ignore flanking letters presented to the left and right of the target (e.g., SSSKSSS ). The typical flankerinterference effect is the finding that RTs are slower when the target is surrounded by response-incompatible flankers than they are when it is surrounded by responsecompatible flankers, indicating that the ignored flankers had been processed at an abstract level (e.g., Eriksen \& Eriksen; Eriksen \& Schultz, 1979; Miller, 1991). Flankerinterference effects have also been demonstrated with word stimuli. For example, Shaffer and LaBerge (1979) required subjects to categorize a centrally located target word into a particular semantic category (metal, furniture, tree, clothing), while ignoring flanking (distractor) words presented above and below the target. The presence of a flanking word in the same response category as the target reliably speeded up RTs to the target word, while the presence of a flanking word from a different response category slowed down RTs to the target word. A similar pattern of results has been replicated by others (Broadbent \& Gathercole, 1990; Lambert, Beard, \& Thompson, 1988; Underwood, 1981), while, under some conditions, the presence of same response-category flankers has been found to slow down RTs to a target word (Lambert et al., 1988; Underwood, Rusted, \& Thwaites, 1983; Underwood \& Thwaites, 1982; White, in press). For present purposes, the direction of the flanker effect is not important; what is important is the demonstration that variations in the meaning of ignored distractors can influence responding to an attended target.

\section{Negative Priming}

The flanker task uses within-trial interference from ignored distractors to index the extent of their processing: The absence of flanker interference effects is equated with the absence of semantic processing. There is an important flaw in this logic, however. As Driver and Tipper (1989) point out, "it is logically possible that an increased physical distinction between attended and unattended stimuli allows the former to be selected more efficiently (i.e., with less distractor influence) without any decline in the analysis of the unattended stimuli" (p. 305; see Allport, 1989, for a similar view). The point is that the absence of flanker-interference effects cannot be taken as evidence for the absence of semantic processing of the distractors. To confirm this, Driver and Tipper found that ignored distractors that did not produce flanker-interference effects on Trial $n$ did produce subsequent NP on Trial $n+1$. The subjects were required to report the number of red letters and to ignore irrelevant black digits in circular arrays during a prime trial. The ignored black digits were always the same digit repeated, and this was either compatible or incompatible with the number of red items in the display. In agreement with previous research (Francolini \& Egeth, 1980), the ignored black digits did not produce any within-trial flanker interference in reporting the number of red items. The more interesting result, however, occurred on the subsequent probe trials. On the probe display, the subject's task was again to report the number of red letters 
and to ignore distracting black letters. It was found that the latency to report the number of red items in the probe display was slower when the black items in the preceding prime display were digits corresponding to the response now required to the probe. For example, if three letters were presented on the probe trial, the subjects were slower to say "three" if they had ignored the digit 3 on the prime trial than they were if they had ignored the digit 2. This finding is important because previous demonstrations that the black distractors produce no withintrial flanker interference had been interpreted as strong evidence that these distractors had simply not been encoded (Francolini \& Egeth, 1980; Kahneman \& Treisman, 1984). Reliable NP on the probe trial from the same distractors that did not produce flanker interference on the prime trial shows this conclusion to have been erroneous.

To further investigate this issue, Fox (1995) obtained measures of flanker interference and NP in a variation of the Eriksen flanker task. Subjects made speeded responses to a target letter while ignoring a distractor letter on a prime trial followed by a probe trial. In agreement with previous studies, precuing the location of the prime target attenuated flanker-interference effects (e.g., Paquet \& Lortie, 1990). Of more interest, however, was the finding that the magnitude of NP from previously ignored distractors did not decline with target precuing. Thus, ignored distractors that produce no within-trial flanker interference can still produce subsequent NP (Driver \& Tipper, 1989; Fox, 1995), indicating that the distractors must have been processed at least to the level of identity.

To summarize, two reviews published in 1986 (Holender, 1986; Johnston \& Dark, 1986) concluded that there was little evidence that ignored distractors receive automatic semantic processing in selective attention tasks. The present paper provides a review of subsequent evidence from the NP paradigm that shows that ignored stimuli are in fact generally processed to a high level in visual selection. It is important to note, however, that this observation does not necessarily support late-selection models of attention. ${ }^{2}$ The more important question concerns whether the phenomenon of NP offers compelling evidence for inhibitory mechanisms in selective attention, or whether NP can be explained without postulating any inhibitory mechanism.

\section{IDENTIFICATION VERSUS LOCALIZATION TASKS}

Most of the studies investigating NP have used filtering, tasks in which the subject selects a target by means of some physical characteristic (e.g., color, location), and then responds to the identity of the object. Indeed, the vast majority of research on NP has looked at priming effects arising from the identity of ignored objects. For example, in Tipper's (1985) picture-naming task, the subject selects the target stimulus by means of a physi- cal feature (color), and then responds to the identity of the target.

Tipper et al. (1990) point out, however, that the demands of this type of task are quite different from many everyday perception-action interactions. They illustrate the point by considering the problem facing a pike fish pursuing six stickleback prey: For an attack to be successful, the pike must first identify its prey and then respond according to the spatial location of the selected stickleback. Tipper et al. developed a select-what respond-where task to better simulate such everyday behaviors. In this task, subjects are required to respond to the location of a target $(O)$, which is presented in one of four possible locations. On some trials, the target is presented alone, while on other trials, a distractor $(+)$ is presented in one of the remaining locations. Flanker interference is indicated by longer RTs in distractor-present prime trials than in distractorabsent prime trials, while NP is indicated by longer RTs when the probe target appears in the same location as the prime distractor than when the probe target is in a different location. In other words, the subjects are sometimes required to respond to a location they have just ignored.

Tipper et al. (1992) introduced a variant of the targetlocalization task in an attempt to more closely simulate interactions in a 3-dimensional environment: Their subjects selectively reached toward a target (red light), while ignoring distracting information (yellow light). The reaching response was substantially slowed if a probe-trial target location had been a prime-trial distractor location. However, this NP effect only occurred if the distractor was in the range of the intended movement; if the distractor was not in the range of the intended reaching response, no NP was observed. Tipper et al. (1992) concluded that the locus of NP in this task is action centered, insofar as the effect appears to be dependent on the relation of the hand position to the target position. An important implication of this result is that the reference frame in which flanker interference and NP are seen may depend on the brain system responsible for the task performance. Subsequent research has indeed confirmed that NP is determined to a large extent by behavioral goals (Milliken et al., 1994; Tipper et al., 1994; see Fox, 1992, for a similar finding with Stroop-like interference).

Results with the original target-localization task (Tipper et al., 1990) suggest that the pattern of results observed is very similar to those observed in the traditional filtering, or select-where respond-what, tasks (e.g., Neill, Valdes, Terry, \& Gorfein, 1992; Tipper et al., 1990; Tipper, Weaver, Cameron, et al., 1991; Tipper, Weaver, Kirkpatrick, \& Lewis, 1991). This similarity across the different tasks is somewhat surprising, since there is neurophysiological evidence to suggest that object identity and object location are processed by separate cortical mechanisms (Felleman \& van Essen, 1991; Ungerleider \& Mishkin, 1982). It has also been shown that it is computationally more efficient to segregate visual processing into two separate systems on the basis of identity and location than it is to combine identity and lo- 
cation information in a single processing system (Rueckl, Cave, \& Kosslyn, 1989).

Consistent with the view that there are two separate cortical systems for identity and location selection, some recent behavioral studies suggest that the processes underlying performance on identity tasks may indeed be somewhat different from those underlying localization tasks. First, Tipper and his colleagues discovered that although young children do not show the typical NP effects to the identity of a distractor (Tipper, Borque, Anderson, \& Brehaut, 1989), they do show NP to its location (Tipper \& McLaren, 1990). A similar dissociation between the two tasks has recently been reported for older adults, who generally show little or no NP in identification tasks (e.g., Hasher, Stoltzfus, Zacks, \& Rympa, 1991; Tipper, 1991). Connelly and Hasher (1993) confirmed that older adults consistently show no NP in target-identification tasks, but in target-localization tasks, reliable NP was found that was similar in magnitude to that shown by younger adults. These dissociations in individual-difference studies will be discussed in a subsequent section. For the moment, they suggest that caution should be used in generalizing from localization to identification tasks, and vice versa (see May, Kane, \& Hasher, in press, for a similar view).

Further indications that different mechanisms may underlie identity and location selection come from a recent series of studies (Milliken et al., 1994; Park \& Kanwisher, 1994; Tipper et al., 1994). Park and Kanwisher have provided compelling evidence that feature mismatching between prime and probe displays can account for NP in the target-localization task. As discussed previously, they found that NP occurred when the symbols occupying the probe-target location changed between the prime and the probe displays, but facilitation was found when the symbols at that location did not change. These results suggest that feature mismatching, and not selective inhibition (or episodic retrieval), underlies spatial NP. In marked contrast, using exactly the same logic, Tipper and Cranston (1985) suggest that selective inhibition, and not feature mismatching, underlies NP in a target-identification task. They required subjects to name a red letter and ignore a green letter in an initial prime display; then, in a subsequent probe display, the subjects were required to name the green letter and ignore the red letter. Suppose that the letter $A$ was presented in green in both displays. According to the mismatching hypothesis, facilitation should occur, since the ignored prime and the subsequent probe both contain the same identity and the same color, and therefore there is no ambiguity. In contrast, according to the selective inhibition hypothesis, the response " $A$ " has been suppressed during the prime display, and therefore should take longer to retrieve in the probe display. Tipper and Cranston found the latter result, and so concluded in favor of distractor inhibition as the better explanation of NP. It should be noted that episodic retrieval can also account for this result, since it does not require a feature mismatch across prime and probe displays. Rather, the critical aspect for this account is that the current target (in the above case, $A$ ) was previously ignored.

To synthesize these results, then, it seems that selective inhibition and episodic retrieval provide better accounts of NP when selection is based on identity (Tipper \& Cranston, 1985), whereas feature mismatching provides a better account when selection is based on location. Both the selective inhibition and the episodic retrieval hypotheses can explain Tipper and Cranston's results, since the current target was recently ignored, while the feature mismatching hypothesis cannot account for these results. In contrast, the results of Park and Kanwisher (1994, Experiment 4) support the feature mismatching hypothesis but not the selective inhibition or the episodic retrieval hypotheses. This is because NP occurred even when the probe target appeared in a location that had not been previously ignored. They also found that NP did not occur when the probe target $(O)$ was presented in the same location as the prime distractor $(O)$. Both the selective inhibition and the episodic retrieval accounts would predict NP in this condition, since the current target location was previously ignored. The feature mismatching hypothesis predicts no NP (or even some facilitation), since there is no mismatch between location and identity across the prime and probe displays.

Milliken et al. (1994) have recently argued that neither the Tipper and Cranston (1985) nor the Park and Kanwisher (1994) experiments provide an optimal method of testing the feature mismatching hypothesis. This is because the subjects are informed of the different selection cues for the prime and probe displays before the experiment, and this might lead them to adopt two shared attention states-one to be used in responding to the prime display, and one to be used in responding to the probe display (see Milliken et al., 1994, note 1). The argument is that the amounts of resources dedicated to detection of target items in the prime and the probe displays may be quite different from each other. In particular, when identifying targets in the prime display, the subjects may already be diverting resources to the probe display. In the NP paradigm, this leads to the further possibility that the subjects may be splitting their resources between the target and the distractor in the prime display, which might lead to an atypically high level of activation of the distractor. To reduce this possibility, Tipper and his colleagues (Milliken et al., 1994; Tipper et al., 1994) have developed a new variant of the target-localization task, in which the target is selected on each of the prime and probe displays on the basis of a color cue. In the new paradigm, a target letter can appear in one of four possible locations (up, down, left, right), in one of four colors. A target letter is selected on the basis of a color cue that appears in the center of the computer screen, either $300 \mathrm{msec}$ prior to the stimulus display or simultaneously with it. The task is to move a joystick in the direction of the letter that is the same color as the central cue. The critical test of the feature mismatching hypothesis lies in the condition in which the prime distractor is identical (in color, letter identity, and 
location) to the probe target. Feature mismatching would predict no NP, and perhaps even facilitation, in this condition, whereas selective inhibition and episodic retrieval accounts would both predict NP, since the prime distractor was ignored. The results showed that there was significant facilitatory priming when the color cue was presented $300 \mathrm{msec}$ prior to the stimulus display, supporting the feature mismatching hypothesis. However, when the color cue was presented simultaneously with the stimulus display, significant NP was observed. Since there was no mismatch between the prime and the probe displays in this condition, the NP effect cannot be explained by the feature mismatching hypothesis. Instead, the NP must be attributed to either distractor inhibition or episodic retrieval of the priming episode. On the former view, NP is attributed to the selective inhibition of distracting information during the prime display. On the latter view, NP is attributed to retrieval of an episode that contains a do-not-respond code for the previously ignored information. Thus, these results provide some support for (and against) all three theories. First, the facilitation with the $300-\mathrm{msec}$ cue can be handled by the feature mismatching hypothesis, but not by the selective inhibition or the episodic retrieval accounts. Second, NP with the simultaneous cue can be handled by both the selective inhibition and the episodic retrieval accounts (which cannot be distinguished), but not by the feature mismatching account.

Thus, it is clear that NP occurs in tasks requiring target identification and in tasks requiring target localization, although the mechanisms producing the NP may differ between the two paradigms (see May et al., in press, for a similar conclusion). Specifically, it seems that feature mismatching is more likely to produce NP in targetlocalization tasks (Milliken et al., 1994; Park \& Kanwisher, 1994) than in target-identification tasks (Tipper \& Cranston, 1985). However, it is important to note that feature mismatching does not seem to be a necessary condition for NP in selection tasks based on either identity (Tipper \& Cranston) or location (Milliken et al.).

\section{AT WHAT LEVEL OF REPRESENTATION DOES NEGATIVE PRIMING OPERATE ?}

An important question to consider is that of whether NP can be accounted for by processes (i.e., selective inhibition, feature mismatching, or episodic retrieval) operating at any particular level of representation. It is possible, for example, that NP reflects processes operating on responses or visual features associated with ignored objects; alternatively, NP may have a more central locus, and operate at the level of semantic representations of ignored objects. Moreover, recent research suggests that the locus of NP effects may be flexible and dependent on the behavioral goals of the task (Tipper et al., 1994). These issues are addressed in the present section. For ease of exposition, the results will be discussed from a selective inhibition point of view, since this is the framework in which most studies have been conducted. At the end of each section, the feature mismatching and episodic retrieval hypotheses will then be considered as alternative explanations of the results.

\section{Responses?}

In some experiments, NP might simply be due to the suppression of a particular response that was activated by an ignored distractor. For example, if a subject ignores the picture of a dog on a prime trial, the verbal response "dog" might then be inhibited, thus producing a delayed response on ignored repetition trials (e.g., Tipper, 1985). Likewise, ignoring the letter $B$ on a prime trial may lead to inhibition of the manual response to this letter on a subsequent probe trial (e.g., Tipper, MacQueen, \& Brehaut, 1988). However, there are a number of NP experiments whose results cannot be attributed to response inhibition. For example, Tipper et al. (1988) directly investigated whether the inhibition of distractors is isolated in particular response modalities or whether NP has a more central locus. The subjects responded to a target letter (identified by a bar-marker) either by naming it (verbal response) or by pressing a button (manual response). Overall, there were reliable flanker-interference effects, as well as reliable NP effects. Importantly, NP was unaffected when the response mode changed across prime and probe displays (e.g., voice response in prime display followed by keypress response in probe display), indicating that NP must have a locus that is independent of response modality.

Neill et al. (1990) also provided evidence that NP cannot be attributed to response inhibition. They introduced a letter-matching procedure that allowed for the uncoupling of the response (same or different) from particular target identities. The subjects judged the second and fourth letters of five-letter strings as being either the same or different, and NP was indicated by slower responses to target letters that matched the ignored distractors appearing in the preceding trial (e.g., $A G A G A$ followed by $S A S A S$ ). If an ignored stimulus is denied access to the response system, rather than to a specific response, NP should not depend on whether the current response is the same as that made in the previous trial (cf. Tipper et al., 1988). In support of this, reliable NP was found under all possible conditions (i.e., same response following different response, same response following same response, etc.), which indicates that NP depends on stimulus identity rather than just on response inhibition (Neill et al., 1990).

Further research by Neill, Valdes, and Terry (1992) demonstrates that NP of specific locations is also not due to response inhibition. In one experiment (Neill, Valdes, \& Terry, Experiment 4), the subjects were required to identify target letters that could appear in one of four locations on a computer screen. The prime trials contained one target letter from the response set $(A, B, C$, or $D$ ) and one distractor letter not from the response set $(E$, $F, G$, or $H$ ). On the probe trials, a single target letter was presented (with no distractor) in one of the four locations. The subject's task on both prime and probe dis- 
plays was to press a key corresponding to the target letter as quickly as possible. NP of specific locations was found both when the target that appeared on the probe trial (e.g., $A$ ) was the same as the target that appeared in the previously ignored location $(A)$, as well as when a new target (e.g., $B$ ) appeared in the previously ignored location on the probe trial. Thus, NP occurred both when there was an identity switch between the prime-target location and the probe-target location and when the same letter appeared as both the prime target and the probe target. This NP effect cannot be attributed to response inhibition, since the responses did not correspond to locations. Finally, it is noteworthy that NP occurred for location in this experiment, even though location was not explicitly relevant to the task.

The research reported here (Neill et al., 1990; Neill, Valdes, \& Terry, 1992; Tipper et al., 1988) demonstrates that NP is not restricted to processes operating exclusively at the level of responses. The results of Neill, Valdes, and Terry (1992) may have been due to feature mismatching, since the degree of mismatch was always greater in the ignored repetition condition than in the control conditions. ${ }^{3}$ This might, in part, explain why NP occurred for locations even though location was not directly relevant to the task (Neill, Valdes, \& Terry, 1992; Experiment 4). This suggestion finds some support in the substantially larger NP effects that were observed when the subjects responded to the same stimulus displays but made a localization response rather than an identity response $(-9 \mathrm{msec}$ vs. $-16 \mathrm{msec}$, respectively; Neill, Valdes, \& Terry, 1992; Experiment 5). However, the other results reported in this section (Neill et al., 1990; Tipper et al., 1988) cannot be explained by a feature mismatching account. To illustrate, in the studies reported by Neill et al., the subjects might respond to the sequence $A G A G A$ followed by $S B S B S$ in a control condition, whereas the sequence in the ignored repetition condition might be $A G A G A$ followed by $S A S A S$. In both conditions, the mismatches between prime and probe trials are equivalent, and yet NP only occurs in the ignored repetition condition. Likewise, in the experiments reported by Tipper et al. (1988; see also Fox, 1994b, 1995), the subjects had to respond to a letter with an adjacent bar-marker and ignore a letter with no barmarker on both prime and probe displays. Thus, the degree of mismatch across prime and probe trials was equivalent for control and ignored repetition probe trials. The only change is that on the ignored repetition trials, the subjects are required to respond to a recently ignored item. Thus, feature mismatching does not provide a coherent explanation of NP in many target-identity tasks (e.g., Fox, 1994b; Neill et al., 1990; Tipper et al., 1988), which is consistent with the finding that feature mismatching is not a necessary condition for NP in target identity tasks (Tipper \& Cranston, 1985). In contrast, both the selective inhibition and episodic retrieval hypotheses can accommodate the results discussed in this section quite easily. Selective inhibition attributes the NP to the suppression of the distractor during the prime trial that leads to a lowered activation threshold for the distractor, resulting in delayed RTs on the probe trial. Episodic retrieval attributes the NP to the automatic retrieval of a processing instance that contains a do-not-respond tag for the distractor.

\section{Physical Features?}

Instead of being due to response factors, it could be that NP is due to processes operating on physical attributes or features of an ignored object. For example, if a picture of a dog is ignored, any stimulus bearing a structural similarity to that object might produce NP. Recent experiments reported by DeSchepper and Treisman (1991) have established that NP can indeed be determined by physical-shape characteristics. They presented line drawings of overlapped nonsense shapes which subjects had to match in a subsequent probe display. It was found that repeating ignored shapes as probe targets produced substantial NP, and this was true even when the shapes presented on the prime trial had never been seen before. This confirmed that the ignored objects had indeed been processed, even though there was no opportunity for across-trial repetition priming (i.e., no shape was repeated during the experiment; see Johnston \& Dark, 1986). These results are also important in showing that NP is not dependent on the availability of a prior perceptual representation of the stimulus.

In DeSchepper and Treisman's (1991) study, NP appears to be specific to the physical features of an ignored object. Neill (1991) also reported an experiment in which perceptual aspects of the stimuli were critical to NP. Following Neill et al. (1990), strings of five letters were presented to the subjects, who were required to match the second and fourth letters as either same or different. The interesting finding was that $\mathrm{NP}$ only occurred when prime and probe displays were in the same letter case (e.g., $A B A B A-D A D A D$ or ababa-dadad), and did not occur when they were in different cases (e.g., $A B A B A$-dadad).

In contrast, however, Allport et al. (1985; Experiment 2) presented a letter-naming task and found that NP was independent of the case of letters across prime and probe displays; that is, equivalent NP was found for same-case prime-probe sequences (e.g., $A-A$ or $a-a$ ) as was found for opposite-case sequences (e.g., $A-a$ or $a-A$ ). As pointed out by Neill, Valdes, and Terry (in press), the discrepancy between the results of Neill (1991) and Allport et al. might be due to the fact that in Allport et al.'s study, naming was independent of letter case, and therefore subjects were likely to base their judgment on more abstract information, while in Neill's study, same matches were physically identical, and therefore subjects probably based their judgments on perceptual attributes. Thus, once again, the evidence indicates that the level of representation at which NP is observed is probably dependent on what level of representation is required for performance of the task (see also Tipper et al., 1994). 
There are several experiments in which the ignored distractor bears little or no physical resemblance to the probe target and in which NP is still observed: (1) In the original NP studies using Stroop stimuli (e.g., DalrympleAlford \& Budayr, 1966; Lowe, 1979; Neill, 1977), the subjects ignored a distracting word, but NP was assessed by means of response to the color denoted by the word. This effect must have occurred at an abstract level of representation that related the word to the color. (2) Tipper and Driver (1988) found that if subjects ignored the picture of a dog during a prime trial, this slowed a subsequent response to the word "dog" on the probe trial. This NP effect between pictures and words cannot be attributed to the inhibition (or retrieval) of physical features of ignored stimuli. (3) Driver and Baylis (1993) have found that ignoring a number presented aurally slows the naming response to the same number when it is presented visually on a probe trial. This demonstrates that NP can be observed cross-modally, and once again, the lack of any physical resemblance between an auditory distractor and a visual target suggests that the effect must be at an abstract level of representation.

\section{Semantic Representations?}

The results discussed in the previous two sections indicate that NP is not simply the result of processes operating either on particular responses or on particular physical features of an ignored item. Rather, the results indicate that ignored stimuli are analyzed to the level of representation required by the task. It is of particular interest to establish whether this remains true when the task requires a semantic level of representation. Most of the previous studies investigated what might be called identity NP, since the ignored distractor was subsequently presented as the probe target. In other words, the ignored distractor and the probe target were the same stimulus. A key test of whether NP operates at a semantic level is to determine whether ignoring a distractor item affects subsequent responding to a semantic associate of that item, rather than to the item itself. This might be called semantic NP. The best evidence for semantic NP would come from a naming task rather than from a categorization task because in the latter, semantic NP could be due to response repetition, which is not a necessary condition, but may be a sufficient condition for producing semantic NP. Table 1 summarizes the NP studies that have investigated semantic NP.

Allport et al. (1985, Experiment 4) addressed the question of whether NP by ignored distractors can affect the processing of probe stimuli that were related to them only in terms of shared categorical or semantic attributes. To this end, they presented superimposed line drawings of familiar objects that formed five categorically related pairs (dog-cat, chair-table, hammer-spanner, trumpetguitar, hand-foot). The task was to remember the target object (cued by color) in the prime display and name the target object (also cued by color) in the probe display. The critical finding was that when subjects selected one drawing in the prime display (e.g., hammer) and ignored a distracting drawing (e.g., hand), the naming of a subsequent categorically related drawing (e.g., foot) was slowed relative to when there was no relation between prime and probe trials. This NP effect by categorically related distractors supports the suggestion that NP is not dependent on physical identity between the prime distractor and the probe target. NP from categorically related distractors was replicated in a subsequent experiment (Experiment 5; see also Tipper, 1985, Experiment 3), which also showed that, at $51 \mathrm{msec}$, identity NP was numerically larger than semantic NP ( $31 \mathrm{msec})$.

A problem in interpreting the results of Allport et al. (1985, Experiments 4 and 5) and Tipper (1985, Experiment 3 ) is that objects within a particular category (e.g., animals) had greater structural similarity to each other than they did to objects from different categories. Therefore, the NP effects might well have been at a structural level, rather than a semantic level, of representation. To identify the level of representation achieved by ignored objects, Tipper and Driver (1988) controlled for the physical similarities between objects by presenting objects in different processing domains that had no features in common (i.e., pictures and words). The subject's task was to select the red item (picture or word) in the prime display and remember its category, and then to overtly categorize the red item (word or picture) in the probe display by giving its superordinate category (e.g., animal for $d o g$ ). As shown in Table 1, the type of stimulus to be ignored was an important determinant of NP. When subjects ignored distracting pictures, significant NP occurred for the within-domain condition (ignore a picture, categorize a picture) as well as the betweendomain condition (ignore a picture, categorize a word). The between-domain effect demonstrated that NP was not dependent on the physical resemblance of objects, confirming that distractors were indeed processed to a semantic level. However, the same pattern was not found when words were the stimuli to be ignored. In this case, neither the within-domain nor the between-domain conditions reached conventional levels of statistical significance. Since the NP effect in the picture-picture condition may be due to structural rather than semantic similarity, the only solid evidence for semantic NP in this study comes from the picture-word condition. It is interesting that significant identity NP was observed in all of the four conditions, which concurs with previous research (Allport et al., Experiment 5).

A number of other studies have confirmed that semantic NP appears to be a fragile effect when the ignored stimuli are words. First, Tipper and Baylis (1987) presented pairs of spatially separated words. The subject's task was, first, to attend to the target word (cued by color) in a prime display and to ignore the distracting word, then to quickly name the category of the target word (again cued by color) in the probe display, and, finally, to recall the category of the prime target. The conditions of interest for the present purposes are those in which the probe target was (1) identical to or (2) semantically related to the previously ignored distractor. The 
Table 1

Summary of Negative Priming Studies Examining Whether Priming Occurs Between Semantic Associates of Ignored Stimuli

\begin{tabular}{|c|c|c|c|c|c|c|}
\hline Authors & $\begin{array}{c}\text { Ignored } \\
\text { Distractor }\end{array}$ & Probe Target & $\begin{array}{c}\text { ISI } \\
(\mathrm{msec})\end{array}$ & Prime Task & Probe Task & $\begin{array}{l}\text { Priming } \\
(\mathrm{msec})\end{array}$ \\
\hline $\begin{array}{l}\text { Allport et al. } \\
\quad(1985, \text { Exp. 4) }\end{array}$ & Picture & Picture & 1,200 & Remember target & Name target & $-20 \dagger$ \\
\hline $\begin{array}{l}\text { Allport et al. } \\
\text { (1985, Exp. 5) }\end{array}$ & Picture & Picture & 1,100 & Remember target & Name target & $-31 \dagger$ \\
\hline $\begin{array}{l}\text { Allport et al. } \\
\qquad(1985, \text { Exp. 8) }\end{array}$ & $\begin{array}{l}\text { Picture } \\
\text { Easy prime selection } \\
\text { Difficult prime selection }\end{array}$ & Picture & 1,200 & Remember target & Name target & $\begin{array}{l}-22 \dagger \\
-14\end{array}$ \\
\hline Tipper \& Driver (1988) & $\begin{array}{l}\text { Picture } \\
\text { Picture } \\
\text { Word } \\
\text { Word }\end{array}$ & $\begin{array}{l}\text { Picture } \\
\text { Word } \\
\text { Word } \\
\text { Picture }\end{array}$ & $\begin{array}{l}1,200 \\
1,200 \\
1,200 \\
1,200\end{array}$ & $\begin{array}{l}\text { Remember category } \\
\text { Remember category } \\
\text { Remember category } \\
\text { Remember category }\end{array}$ & $\begin{array}{l}\text { Name category } \\
\text { Name category } \\
\text { Name category } \\
\text { Name category }\end{array}$ & $\begin{array}{l}-47 \ddagger \\
-25 \dagger \\
-19 \\
-29^{*}\end{array}$ \\
\hline $\begin{array}{l}\text { Tipper \& Baylis } \\
\text { (1987, Exp. 2) }\end{array}$ & Word & Word & 1,300 & Remember category & Name category & -.5 \\
\hline $\begin{array}{l}\text { Enright \& Beech } \\
\text { (1993b) }\end{array}$ & Word & Word & 500 & Remember category & Name category & $-27 \ddagger$ \\
\hline $\begin{array}{l}\text { Chiappe \& MacLeod } \\
\text { (in press) }\end{array}$ & Word & Word & 600 & $\begin{array}{l}\text { Name or categorize } \\
\text { target }\end{array}$ & $\begin{array}{l}\text { Name or categorize } \\
\text { target }\end{array}$ & -3 \\
\hline Yee (1991, Exp. 1) & $\begin{array}{l}\text { One or two words } \\
\text { One ignored word } \\
\text { Two ignored words }\end{array}$ & Letter string & ca. 826 & Categorize shape & Lexical decision & $\begin{array}{c}0 \\
-36 t\end{array}$ \\
\hline Yee (1991, Exp. 2) & $\begin{array}{l}\text { Two words or word-and- } \\
\text { nonsense string } \\
\text { Ignored word and string } \\
\text { Two ignored words }\end{array}$ & Letter string & 500 & Categorize shape & Lexical decision & $\begin{array}{c}+7 \\
+29 \dagger\end{array}$ \\
\hline Yee (1991, Exp. 2) & $\begin{array}{l}\text { Nonsense string } \\
\text { Ignored word and string } \\
\text { Two ignored words }\end{array}$ & Letter string & 600 & Categorize shape & Lexical decision & $\begin{array}{c}-2 \\
-24 \dagger\end{array}$ \\
\hline \multirow[t]{5}{*}{$\begin{array}{l}\text { Fuentes \& Tudela } \\
\text { (1992, Exp. 2) }\end{array}$} & $\begin{array}{l}\text { Two words or word } \\
\text { and row of } X s\end{array}$ & Letter string & 850 & No overt response & Lexical decision & \\
\hline & $\begin{array}{l}\text { Two ignored words } 2^{\circ} \\
\text { from fixation }\end{array}$ & & & & & $-11^{*}$ \\
\hline & $\begin{array}{l}\text { Two ignored words } 3.6^{\circ} \\
\text { from fixation }\end{array}$ & & & & & +7 \\
\hline & $\begin{array}{l}\text { Ignored word and } X s \\
2^{\circ} \text { from fixation }\end{array}$ & & & & & $+20 \dagger$ \\
\hline & $\begin{array}{c}\text { Ignored word and } X \mathrm{~s} \\
3.6^{\circ} \text { from fixation }\end{array}$ & & & & & $+17 \dagger$ \\
\hline Fox (1994, Exp. 3) & Two words & Letter string & ca. 857 & Categorize number & Lexical decision & $-10 \ddagger$ \\
\hline
\end{tabular}

Note-The table shows the type of ignored distractor on the prime display, the type of stimulus on the probe display, the interstimulus interval (ISI) between the prime and the probe display, the nature of the task required on the prime and probe displays, and the magnitude of priming observed. ${ }^{a}$ Here and subsequently, this refers to task required on the target item. ${ }^{*} p<.10 . \quad \dagger p<.05 . \quad \ddagger p<.01$.

by-now-familiar result was found: Significant identity NP occurred but no semantic NP was observed. In contrast, when priming from the attended prime target was investigated, both identity and semantic facilitation occurred. Enright and Beech (1993b), however, have reported contrasting results using an almost identical procedure to that of Tipper and Baylis. They again found that identity NP (at $42 \mathrm{msec}$ ) was numerically larger than semantic NP (27 msec), but in this case, the latter was also significant. It should be noted that all of the subjects in Enright and Beech's experiment had a psychological disorder, so the results may not be typical of the general population. It is of interest, however, that in this study, significant semantic NP was found from previously ignored words.

A recent study (Chiappe \& MacLeod, in press) directly compared identity and semantic NP effects from ignored words. Chiappe and MacLeod presented prime and probe trials that consisted of a to-be-responded-to word printed in blue and a to-be-ignored word printed in white. In the identity NP condition, the same word that was ignored during the prime trial was presented as the probe target. In the semantic NP condition, the probe target was categorically related to the ignored prime. A main focus of the experiment was to determine whether NP was bound to particular tasks. To do so, two tasks were used that were manipulated factorially on prime and probe trials. Thus, one group of subjects named both the prime target and the probe target; another group named the prime target and categorized the probe target; another group categorized the prime target and named the probe target; and the final group categorized both the prime target and the probe target. It should be noted that the task shifts in this experiment deal with the issue of 
response repetition, which is a problem in categorization tasks, as response repetition itself may produce the NP effect. Overall, the results were very similar to those of previous research (Allport et al., 1985; Tipper \& Driver, 1988 ), in that they showed very reliable identity NP, but no overall semantic NP. With regard to identity NP, this did not differ across the four conditions, indicating that identity NP is not bound to particular tasks. In marked contrast to the identity NP effects, there was no evidence for semantic NP.

The foregoing pattern of results (i.e., reliable identity NP, fragile semantic NP) cannot distinguish among the three accounts of the NP effect. To illustrate this, in the task described by Chiappe and MacLeod (in press), the subject may have ignored the word hatchet (printed in white) on the prime trial and then responded to the word hatchet (printed in blue) on the probe trial. On the prime trial, the word's identity (hatchet) is associated with the color white, whereas on the probe trial, the same identity is now associated with the color blue. This feature mismatch might produce an ambiguity that results in a slight delay, hence producing identity NP (see Allport et al., 1985; Lowe, 1979). However, in the semantic NP condition, the degree of mismatch between the prime and probe displays is presumably less, and therefore there should be less NP, which, of course, is exactly what happens. Thus, feature mismatching can provide a good explanation as to why NP is more likely to occur with identical items than with related items. Against this, however, it should be remembered that feature mismatching does not seem to be necessary for identity NP in a letter-identification task (Tipper \& Cranston, 1985).

The observation of greater identity NP than semantic NP does not present a problem for either the selective inhibition or the episodic retrieval hypotheses. On the selective inhibition account, since identity NP involves a structural as well as a semantic overlap between the ignored distractor and the subsequent probe, it is reasonable to suppose that the structural as well as the semantic features of a stimulus are inhibited. This double inhibition would lead to a greater magnitude of identity NP than semantic NP. Similarly, on the episodic retrieval account, it seems plausible that a probe target provides a more potent retrieval cue for an identical object than for a related object. Once again, this mechanism would predict more identity NP than semantic NP. Thus, the pattern of more identity NP than semantic NP can be accounted for by each of the three different accounts of NP. It should be noted as well that the three theories can also explain significant semantic NP if it is assumed that meaning is included in the distractor's encoded representation.

A number of other studies have used word stimuli in successive distractor-target presentations in order to determine whether priming from ignored words is semantically based (Fuentes, Carmona, Agis, \& Catena, 1994; Fuentes \& Tudela, 1992). The general technique is to present a prime display that contains a to-be-attended word at fixation (although no overt response is required) and a to-be-ignored word in a spatially separate location. The attended and ignored words are always unrelated to each other, and are followed by a single probe letter string at fixation to which a lexical decision is required. A probe word can be semantically related or unrelated to either the attended or the ignored prime. Under these conditions, semantic (positive) priming from ignored primes has been reported (di Pace, Longoni, \& Zoccolotti, 1991), and seems to decrease in magnitude as the ignored and attended primes are moved closer together (Fuentes \& Tudela). Interestingly, Fuentes and Tudela found that there was a tendency for priming to become negative at the closest proximity investigated $\left(2.3^{\circ}\right)$, although this did not reach significance. This variation in NP with target-distractor separation is discussed in a subsequent section.

The foregoing studies are important because they preclude the possibility that processing of a prime target may produce spreading activation that itself primes the distractor's representations. This is because the distractors and targets were always unrelated within a trial. Another method of preventing spreading activation between attended and ignored stimuli is to require subjects to respond to an attended target during a prime display that is in a different stimulus domain to that of concurrently presented distractors. The semantic processing of the distractors can then be assessed on a subsequent probe trial. Such a technique was used by Yee (1991), who required subjects to categorize a geometrical figure in a prime display while ignoring distractor words presented $4.5^{\circ}$ of visual angle above and/or below the target. Distractor words were not repeated during the experiment, and appeared $200 \mathrm{msec}$ after the onset of the target figure. In a subsequent probe task, the subjects had to make a lexical decision to a centrally located letter string. No significant effects emerged when a single distracting word appeared in the prime display; however, when two distractor words were presented, RTs to a semantically related word in the lexical decision task were significantly slowed relative to conditions with unrelated distractors. ${ }^{4}$ In a subsequent experiment, significant facilitation occurred with a prime-probe stimulus onset asynchrony (SOA) of $500 \mathrm{msec}$, while significant NP was found when the SOA was increased to $600 \mathrm{msec}$ (Yee, Experiment 2).

In an adaptation of Yee's (1991) task, a small but significant NP effect of $10 \mathrm{msec}$ has been observed (Fox, 1994a, Experiment 3). In this study, the subjects categorized a number presented at fixation as either odd or even, while ignoring spatially separated distractor words during a prime trial. On a subsequent probe trial, a letter string was presented, to which subjects made a lexical decision. In agreement with Yee, when the probetarget word was semantically related to a previously ignored distractor word, reliable NP was found.

To summarize, it seems that the semantic locus of NP effects is far from well established (for an alternative view, see May et al., in press). When subjects ignore pictures, evidence for semantic NP is relatively strong (All- 
port et al., 1985; Tipper, 1985; Tipper \& Driver, 1988), although with the exception of Tipper and Driver's (1988) picture-word condition, all of these NP effects may have been at a structural level of representation. The evidence is very inconsistent when the distractors to be ignored are words. While there are some positive results (Enright \& Beech, 1993b; Fox, 1994a; Yee, 1991 [with two distractor words]), other studies have failed to find significant semantic NP (Chiappe \& MacLeod, in press; Fuentes \& Tudela, 1992; Tipper \& Baylis, 1987; Yee, 1991 [when a single distractor word was presented]).

One distinction that might shed some light on the inconsistencies observed in semantic NP with words is the contrast between associative and categorical priming. In Chiappe and MacLeod's (in press) study, word pairs were categorically related but were not strong associates, and this might explain the absence of semantic NP. Some support for this notion comes from an examination of the materials used in the studies that did find significant semantic NP with words. Fox (1994a) and Yee (1991) both presented highly associated word pairs and obtained semantic NP (at least with two distracting words). On the other hand, some studies that failed to obtain semantic NP also used word pairs that were both associatively and categorically related (Enright \& Beech, 1993b; Tipper \& Baylis, 1987; Tipper \& Driver, 1988). As to whether NP is produced by an associative or a categorical relation between ignored distractors and subsequent targets is therefore unclear. A direct comparison between associatively and categorically related word pairs in a single experiment would be informative on this issue. It may also be the case that the type of task required on the probe trial (e.g., naming vs. lexical decision) may explain the differences between studies. May et al. (in press) argue that a lexical decision task on the probe trial is likely to induce retrieval mechanisms, so that NP under these conditions may be due to retrieval mechanisms. Thus the significant semantic NP observed from ignored words (Fox, 1994a; Yee, 1991) may have been due to retrieval mechanisms. As pointed out by May et al., there is a need to investigate more directly the impact of the type of probe task on the magnitude of NP.

\section{Is the Locus of Negative-Priming Effects Flexible?}

To recapitulate, it seems that (1) when the task required involves feature comparison, NP can be associated with early perceptual features of ignored objects (DeSchepper \& Treisman, 1991); (2) when the task requires stimulus categorization, NP can be associated with the semantic properties of the ignored object (Tipper \& Driver, 1988); and (3) when subjects have to reach directly for a target object, NP appears to be associated with action-centered internal representations of the ignored object rather than with perceptual or semantic properties (Tipper et al., 1992). On the basis of these results, Tipper and his colleagues (Milliken et al., 1994; Tipper et al., 1994) have suggested that the processing of an object leads to the development of multiple percep- tual representations relating to the various properties of the object (e.g., color, location, identity, etc.). They argue that the inhibition of ignored information can then be directed to any one of these representational domains, depending on the current goal states. This apparent flexibility of inhibitory mechanisms is consistent with the recent finding that NP from a distractor's color, location, or identity is determined to some extent by the behavioral goal of the task (Tipper et al., 1994). When the goal was to indicate the location of a target object, the location, but not the identity, of the ignored distractor produced an NP effect. Conversely, if the task was to identify a target object, the distractor's location did not produce NP. It is important to note, however, that significant NP from the identity of ignored distractors was also not observed when the task required subjects to respond to the identity of a target, which would be predicted by the hypothesis. Furthermore, Neill, Valdes, and Terry (1992) found NP specific to a particular location even when location was not required by the task, although, as noted previously, this may have been due to feature mismatching. Nevertheless, these inconsistencies suggest caution in concluding that inhibition is flexible and is applied at the level of representation that is required for task performance.

The apparent flexibility of NP effects may be because mismatches between prime and probe displays are more salient when the mismatch is between a prime and a probe at the same level of representation. Similarly, the level of representation required to respond to the probe target is likely to provide a more salient memory cue for previously ignored information at the same level of representation. Therefore, the results discussed here cannot distinguish among the three competing explanations of NP.

\section{FACTORS THAT INFLUENCE NEGATIVE PRIMING}

The studies reviewed so far show that each of the three different explanations of the NP effect (selective inhibition, feature mismatching, and episodic retrieval) has some results in its favor. However, none of the theories can provide a principled account of all of the results discussed so far. The present section attempts to provide information about this issue by considering studies that have manipulated various experimental factors in order to examine what effect they have on NP. In the most general terms, if NP is due to selective inhibition applied during the prime trial, manipulations on the prime trial would be most likely to influence the magnitude of NP; manipulations on the probe trial would be less likely to have an impact on NP. In contrast, if NP is due either to a lack of correspondence between features on the prime and probe trials (i.e., feature mismatching) or to episodic retrieval of the priming episode elicited by processing of a probe item (i.e., episodic retrieval), manipulations on the probe trial might be expected to have more impact on NP than manipulations on the prime 
trial. With this in mind, the current section reviews a number of factors that are known to influence the magnitude or pattern of NP effects.

\section{An Emphasis on Accuracy Versus an Emphasis on Speed}

A number of studies, summarized in Table 2, have investigated whether instructing subjects to emphasize speed, as opposed to accuracy, of responding makes any difference to the pattern of NP observed. The general finding is that when subjects are instructed to be as accurate as possible, reliable NP is observed for manual responses to Stroop stimuli (Neill \& Westberry, 1987, Experiments 1 and 2), as well as for naming letters (Neumann \& DeSchepper, 1992, Experiment 2). In contrast, when subjects are encouraged to respond as quickly as they can, giving accuracy a low priority, facilitation, or PP, from ignored distractors, is the typical result (Neill, 1977, Experiment 2; Neill \& Westberry, 1987, Experiment 1; Neumann \& DeSchepper, 1992, Experiment 2).

On the selective inhibition account, this reversal of NP to PP from ignored distractors when speed is emphasized supports the notion that there is an initial automatic activation of all stimuli in a display, followed by an inhibitory narrowing-down process (Keele \& Neill, 1978; Neill, 1989). Assuming that distractor representations are initially activated (e.g., Neill, 1989: Neumann \& DeSchepper, 1992), there is presumably some time lag before the inhibitory mechanism can be fully implemented. If subjects are forced to respond very rapidly, the probe target might be presented when the representations of the previously ignored distractor are still activated, and hence facilitation is observed. Some support for this notion comes from the finding that PP is observed from ignored distractor words when the SOA between the prime and the probe display is $500 \mathrm{msec}$, while a 600-msec SOA produces inhibitory priming (Yee, 1991, Experiment 2). Whatever the reason, the degree to which a distractor is inhibited during the prime trial clearly depends on the demand for accuracy versus speed.
The feature mismatching hypothesis does not seem to be able to explain this result, since the degree of mismatch between prime and probe episodes remains constant, regardless of how quickly or slowly the subject responds. However, it is possible that when subjects respond very quickly, they are less likely to encode irrelevant information in episodic memory (Neill, Valdes, Terry, \& Gorfein, 1992). The assumption is that if ignored information is less likely to be encoded, it is less likely to be retrieved, and NP will therefore be reduced or eliminated. This suggestion provides a good account of the effects on NP of speed stress versus accuracy stress only if priming disappears completely when the subjects are encouraged to respond quickly. In fact, this is not what happens. As shown in Table 2, priming does not generally disappear with speed stress; rather, it becomes positive (Neill, 1977, Experiment 2; Neumann \& DeSchepper, 1992, Experiment 2). This result presents a difficulty for the episodic retrieval account (as well as for the feature mismatching account). Since distracting information clearly is encoded, why does this information produce PP rather than NP? One possibility is that the facilitation might be produced by some residual activation of the ignored distractors. As discussed previously, the selective inhibition hypothesis can provide a very plausible explanation for this pattern of results.

\section{Selection Difficulty on the Prime Trial}

An assumption of the selective inhibition hypothesis is that a primary function of an inhibitory mechanism is to prevent competing distractors from taking control of thoughts or actions. If this is correct, increased inhibition of distractors might be expected under conditions in which selection of the target is particularly difficult. Thus, increased NP would be expected with increased selection difficulty. However, under conditions of difficult selection, it is probable that irrelevant distractors will receive more extensive processing than they do under conditions of easy selection. On the assumption that more extensively processed distractors are more likely to be retrieved, both the feature mismatching and

Table 2

Summary of Negative-Priming Studies Examining the Effects of Instructional Emphasis on Speed Versus Emphasis on Accuracy

\begin{tabular}{|c|c|c|c|}
\hline Authors & Stimuli & Type of Task & $\begin{array}{c}\text { Priming } \\
\text { (msec) }\end{array}$ \\
\hline Neill (1977, Exp. 2) & Color-words & $\begin{array}{l}\text { Manual response } \\
\text { Emphasis on speed }\end{array}$ & $+9^{*}$ \\
\hline $\begin{array}{c}\text { Neill \& Westberry } \\
\text { (1987, Exp. } 1)\end{array}$ & Color-words & $\begin{array}{l}\text { Manual response } \\
\text { Emphasis on speed } \\
\text { Emphasis on accuracy }\end{array}$ & $\begin{array}{l}+17 \\
-26^{*}\end{array}$ \\
\hline $\begin{array}{l}\text { Neill \& Westberry } \\
\quad(1987, \text { Exp. } 2)\end{array}$ & & Emphasis on accuracy & $-13^{*}$ \\
\hline $\begin{array}{l}\text { Neumann \& DeSchepper } \\
\quad(1992, \text { Exp. 2) }\end{array}$ & Letters & $\begin{array}{l}\text { Letter naming } \\
\text { Emphasis on speed } \\
\text { Emphasis on accuracy }\end{array}$ & $\begin{array}{l}+8^{*} \\
-10 \dagger\end{array}$ \\
\hline
\end{tabular}


episodic retrieval hypotheses would also expect increased NP with increased selection difficulty on the prime trial.

Allport et al. (1985, Experiment 8) directly tested whether the difficulty of target selection on the prime trial would influence the magnitude of NP observed. Spatially separated line drawings were presented, and subjects were instructed to attend to the green object in the prime display and to ignore the irrelevant red object. When the subsequent probe display was presented, the subjects were to name the green object as quickly as possible, and then recall the green object from the preceding (prime) display. The line drawings were presented for $150 \mathrm{msec}$; then they were pattern masked, (1) in an easy-selection condition, in which the prime target appeared at fixation and the distractor appeared randomly $5^{\circ}$ to the right or left of fixation; and (2) in a difficult-selection condition, in which the prime target and distractor drawings appeared equidistant from fixation at the diagonally opposite corners of an imaginary square separated by approximately $5^{\circ}$ center to center. The probe display consisted of a target (in green) and a superimposed distractor (in red). Although the overall interaction between ease of selection and NP was not significant, reliable NP was found following easy selection $(22 \mathrm{msec}$ ), but the NP effect of $14 \mathrm{msec}$ under difficult selection was not statistically reliable. Thus, there is no strong evidence from this experiment that difficult selection increases the magnitude of NP observed.

Another means of examining task difficulty and NP is to manipulate the activation level of to-be-ignored distractors, on the assumption that highly activated/primed distractors are more difficult to ignore than unprimed distractors. Using this logic, Malley and Strayer (in press) demonstrated substantial identity NP in a wordnaming task when the to-be-ignored words had been repeated many times during the experiment. In contrast, when a word was presented only twice (once as a prime distractor and once as a probe target), no identity NP was observed (which contrasts with DeSchepper \& Treisman's [1991] results with nonsense shapes). One interpretation of Malley and Strayer's results is that NP only occurs under conditions of difficult selection (i.e., when distractors are highly primed). It should be noted, however, that it is not clear whether it is the difficulty of ignoring distracting words on the prime trial or on the probe trial that is responsible for the results. The increase in NP may well have been due to increased difficulty on the probe trial (see Moore, 1994).

Spatial separation of targets and distractors. Several studies have shown that the degree of spatial separation between target and distractor objects on the prime trial influences the magnitude of subsequent NP. It seems reasonable to assume that close target-distractor separation makes selection of the target more difficult than far target-distractor separation. DeSchepper and Treisman (1991) ran one experiment in which relevant and irrelevant nonsense shapes (cued by color) shared a contour so that, perceptually, the to-be-attended shape was the "fig- ure" and the unattended shape was the "ground." In another condition, exactly the same shapes were presented, but this time as perceptually separate objects. The question was whether NP would occur both when the previously irrelevant ground became the relevant figure on the next trial and when the same shapes were spatially separate. It is important to note that displays were similar for both the prime and probe trials. The results showed that NP only occurred when the relevant and irrelevant shapes were perceptually integrated, while nonsignificant facilitation occurred when the shapes were spatially separate objects. In other experiments, however, DeSchepper and Treisman (1991) established that substantial NP does occur when meaningless shapes are presented as perceptually distinct relevant and irrelevant objects that are superimposed on each other. Overall, this pattern of results indicates that a greater magnitude of NP is observed when relevant objects are more difficult to disentangle from irrelevant objects (on both prime and probe trials).

Some support for this notion was provided by Fuentes and Tudela (1992), who manipulated spatial separation of target and distractor items on the prime display only. The subjects attended to a target word (but made no response) while ignoring a spatially displaced distractor word on a prime trial, and then made a lexical decision to a single letter string (no distractor) on a probe trial. When the ignored distractors were presented at more than $4^{\circ}$ of visual angle from fixation, facilitation, or PP, was observed from the ignored words (Fuentes et al., 1994; Fuentes \& Tudela, 1992; but see Yee, 1991, for contrasting results); when the distractor was around $2^{\circ}$ from fixation, however, there was a tendency for priming to become negative, although this just failed to reach significance (Fuentes \& Tudela, Experiment 2). Fox (1994b) also manipulated the spatial separation between targets and distractors on the prime trial in a version of the Eriksen flanker task. Pairs of letters were presented, with the prime-target letter (cued by an adjacent barmarker) being randomly presented to the left or right of fixation. The spatial separation of the target and distractor letters on the prime trial was manipulated so that the distracting letter was either near (i.e., $.97^{\circ}$ of visual angle), medium $\left(1.7^{\circ}\right)$, or far $\left(2.6^{\circ}\right)$ in relation to the target letter (note that $2.6^{\circ}$ was a near position in the Fuentes \& Tudela study). In agreement with much previous research, the magnitude of flanker interference from ignored distractors increased substantially as the distractor letter was moved closer to the target letter (e.g., Miller, 1991). Of more interest, however, was the finding that NP from ignored distractors also increased in magnitude with decreasing target-distractor separation on the prime trial $\left(38 \mathrm{msec}\right.$ at the $.97^{\circ}$ separation, compared with $9 \mathrm{msec}$ at the $2.6^{\circ}$ separation; see also Valdes, 1993, cited in Neill et al., in press, for similar results). These results indicate that the magnitude of NP increases in a letter-identification task when a target letter is more difficult to distinguish from a distractor letter. As noted previously, NP in this paradigm (Fox, 
1994b; Tipper et al., 1988) cannot be due to feature mismatching, since the degree of mismatch between control and ignored repetition trials is equivalent.

Overall, then, it seems that near distractors produce more NP than far distractors. Indeed, taken together, the results suggest a monotonic decrease in NP as distractor eccentricity increases (Fox, 1994b; Fuentes \& Tudela, 1992; an exception is Yee's [1991] result of NP from ignored words at $4^{\circ}$ ). The selective inhibition hypothesis attributes this pattern to inhibition's being responsive to the increased likelihood of disruption from irrelevant distractors. On the other hand, the episodic retrieval hypothesis might suggest that near distractors are more likely to be encoded than far distractors, and hence that they have a greater potential for producing NP. If NP is caused by retrieval of an item that is associated with a do-not-respond tag which conflicts with the current respond tag (Neill, Valdes, Terry, \& Gorfein, 1992), why does facilitation occur when that item is far away (Fuentes \& Tudela)? One possibility is that distant distractors are too far away for either that item's features or a do-notrespond tag to be consciously encoded, and that residual activation then produces a PP effect.

While the magnitude of NP varies with targetdistractor separation (Fox, 1994b; Fuentes et al., 1994; Fuentes \& Tudela, 1992; Valdes, 1993, cited in Neill et al., in press), it is also true that well-separated distractors can and do produce significant NP. This has been shown when the ignored distractors were letters (Fox, 1994b, in press; Neumann \& DeSchepper, 1991, 1992, Experiment 1; Tipper \& Cranston, 1985, Experiment 2; Tipper et al., 1988), pictures (Allport et al., 1985, Experiments 6, 7, and 8; Tipper, Weaver, Cameron, et al., 1991, Experiment 1), and words (Fox, 1994a; Yee, 1991). To illustrate, Neumann and DeSchepper (1991) investigated NP in a color-naming task in which target and distractor letters were separated by more than $2^{\circ}$ of visual angle on both prime and probe displays and presented for just $50 \mathrm{msec}$. Reliable NP, as well as visual repetition priming (i.e., faster responding when the prime target became the probe target), were found. Moreover, this facilitation from attended repetition priming was enhanced if the distractors were also repeated, which indicates that previously ignored distractors were less available for producing flanker interference when they were repeated on the subsequent trial (see also DeSchepper \& Treisman, 1991). The selective inhibition account attributes this result to the reduced availability of inhibited distractors to produce flanker interference. The feature mismatching hypothesis does not seem able to explain this result since, if anything, the mismatch between prime and probe displays was less when distractors were repeated. However, the episodic retrieval hypothesis can account for this result on the basis of there being no conflict between the retrieved distractor (do not respond) and the current distractor (do not respond), so that some facilitation would be expected.
The relation between flanker interference and NP. A more direct index of selection difficulty on the prime trial is provided by the magnitude of flanker interference that occurs. On a memory retrieval account of NP, it might be expected that the more extensively they are encoded, the more interference distractors would produce. Thus, the feature mismatching and episodic retrieval hypotheses might predict a positive relation between the magnitude of flanker interference and NP. In contrast, if NP reflects an inhibitory mechanism that presumably serves to reduce the amount of flanker interference from ignored objects, an inverse relation might be expected between flanker interference and NP. However, an inhibition account could also explain a positive relation between the two measures, on the assumption that inhibition might be reactive to increasing interference in the visual environment (Neill et al., in press). In other words, an inhibitory mechanism might only be implemented if flanker interference is high. Thus, a positive relation between flanker interference and NP is not diagnostic of what might be causing NP, while an inverse relation would support an inhibitory account. When flanker interference and NP have been measured in within-subjects designs, a number of studies have indeed found a positive relation between the magnitude of flanker interference and NP (Fox, 1994b; Neill \& Lissner, 1988; Neill, Valdes, \& Terry, 1992). For example, in a letter-matching task, Neill and Lissner found that conditions that induced greater levels of flanker interference also produced a greater magnitude of NP. Further evidence comes from the finding of increased NP when stimulus-response (S-R) mappings are incompatible (Neill, Valdes, \& Terry, 1992, Experiment 6). In a target-localization task, one group of subjects pressed the rightmost key if a target appeared in the rightmost position of a display, and the leftmost key if the target appeared in the leftmost position (for both prime and probe displays). For another group of subjects, these response assignments were reversed, so that they pressed the rightmost key to indicate the leftmost position, and vice versa. Incompatible $\mathrm{S}-\mathrm{R}$ mappings produced substantially more NP $(52 \mathrm{msec})$ than did compatible S-R mappings $(16 \mathrm{msec})$. Since incompatible $S-R$ mappings are associated with increased levels of Strooplike interference (e.g., Fox, 1992; McClain, 1983), this pattern suggests that conditions associated with increased flanker interference are also associated with increased NP.

As mentioned previously, these findings of a positive relation between flanker interference and NP can be accounted for by each of the three theories of NP. However, the selective inhibition account leads to a different prediction from that of either the feature mismatching or episodic retrieval accounts. The logic is that when there is stronger inhibition (i.e., more NP), less flanker interference should occur, on the assumption that a function of inhibition might be to reduce the degree of flanker interference from competing distractors. By the same token, if inhibition is not applied strongly, greater flanker 
interference would be expected. Neither the feature mismatching nor the episodic retrieval hypotheses would expect such an inverse relation between flanker interference and NP. Several individual-difference studies have indeed found evidence for such an inverse relation between flanker interference and NP. To illustrate, Beech and his colleagues (Beech, Baylis, Smithson, \& Claridge, 1989; Beech \& Claridge, 1987; Beech, McManus, Baylis, Tipper, \& Agar, 1991; Beech, Powell, McWilliam, \& Claridge, 1989) have demonstrated that subjects with high schizotypical personality traits are more susceptible to flanker interference from ignored distractors and also show less NP from the same distractors. A very similar pattern has been found both for older adultswho tend to show heightened distractibility and reduced NP relative to younger adults (Hasher et al., 1991; Tipper, 1991)-as well as for young children (Tipper et al., 1989). These individual differences in NP will be discussed further in a subsequent section.

While an inverse relation between flanker interference and NP is common in individual-difference studies, there is no evidence for such a relation within the same individual. Rather, within-subject designs have shown either a positive relation between flanker interference and NP, as already discussed, or a surprising degree of independence between flanker interference and NP (Beech, Agar, \& Baylis, 1989; Driver \& Tipper, 1989; Fox, 1994b, 1995; Tipper, Weaver, Kirkpatrick, \& Lewis, 1991). For example, while Fox (1994b, Experiment 1 ) found a positive relation between the magnitude of flanker interference and NP with decreasing targetdistractor separation on the prime trial, the changes in the two effects did not appear to be parallel. Flanker interference decreased most from the medium to the far separations that were used, while NP decreased most from the near to the medium separations. This apparent dissociation between flanker interference and NP was confirmed by the finding that precuing the location of the prime target led to a significant reduction in the amount of flanker interference from ignored distractors, while the magnitude of NP did not decrease (Fox, 1994b, Experiment 2). This is reminiscent of previous findings that ignored distractors produce similar levels of NP, both under conditions in which they produce no Strooplike interference, as well as under conditions in which significant flanker interference is observed (Allport et al., 1985; Driver \& Tipper, 1989; Fox, 1995). Conversely, Beech, Agar, and Baylis (1989) found differences in the magnitude of NP across different types of stimuli (color-words vs. pseudocolor-words), while the magnitude of flanker interference remained the same. Similarly, pattern masking of both targets and distractors on the prime and probe displays has been shown to reduce the magnitude of NP, while leaving flanker interference unaffected on both target localization (Tipper, Weaver, Kirkpatrick, \& Lewis, 1991, Experiment 2) and target identification (Fox, 1995) tasks.

The above research indicates that these two indices of processing of ignored distractors (i.e., flanker interfer- ence and NP) can be dissociated. As noted by Tipper, Weaver, Cameron, et al. (1991), however, a dissociation between flanker interference and NP at the empirical level need not necessarily imply a dissociation of underlying mechanisms. This is particularly true when both excitatory and inhibitory mechanisms - which act on the attended and the ignored information, respectively-are proposed. It might well be the case that precuing primetarget location, for example, results in changes in the excitatory component of selection but leaves the inhibitory component unchanged. In this context, it is interesting to point out that a recent neural network model of inhibitory selection (Houghton \& Tipper, 1994) shows that even though inhibition is a mechanism of selection that determines flanker interference, so that flanker interference and NP should be associated, dissociations are also possible. Tipper argues that this is because there are multiple mechanisms of selection, not just the one mechanism of inhibition. It is quite possible that activity levels in other systems might mask any associations between measures of flanker interference and inhibition (Tipper, personal communication, July 6,1994$)$. If there are indeed multiple mechanisms of selection, it seems likely that each of these will be differentially responsive to different aspects of the visual environment. This makes it extremely difficult to make specific predictions about what relations would be expected between various indices that are assumed to measure one or other of these underlying mechanisms. It is therefore of increasing importance to develop mathematically specific models of selective attention that allow more precise empirical predictions to be made (e.g., Houghton \& Tipper).

Summary. What can be concluded from this section? On the one hand, there are some indications that when prime distractors are more likely to elicit a wrong response (e.g., when they are closer to the target), a greater magnitude of subsequent NP is observed (DeSchepper \& Treisman, 1991; Fox, 1994b; Fuentes \& Tudela, 1992; Neill \& Lissner, 1988; Neill, Valdes, \& Terry, 1992; Valdes, 1993, cited in Neill et al., in press; see also Malley \& Strayer, in press). Likewise, Milliken et al. (1994) also found a small increase in NP with increasing difficulty in prime-target selection in their target-localization task. On the other hand, a number of studies report significant NP under conditions in which target selection is relatively easy (e.g., Driver \& Tipper, 1989; Fox, 1995 Yee, 1991), and Allport et al. (1985) found no interaction between the difficulty of target selection and the magnitude of NP. Finally, several studies find no relation at all between flanker interference and NP (Beech, Agar, \& Baylis, 1989; Driver \& Tipper, 1989; Fox, 1995; Tipper, Weaver, Kirkpatrick, \& Lewis, 1991). As pointed out previously, an inverse relation between flanker interference and NP would, theoretically, be most diagnostic, since this pattern is only predicted by the selective inhibition account. However, the only evidence for such a pattern comes from individual-difference studies. In within-subject designs with healthy young adults, the two measures are either positively related or dissociated. 


\section{Number of Distractors on the Prime Trial}

The above section discussed a number of studies that examined the role of selection difficulty in producing NP by manipulating variables such as target-distractor separation or precuing of target location on the prime trial. All of the foregoing NP studies presented a single target to be attended to and a single distractor to be ignored during a prime trial. An interesting question concerns what would happen if there were more than one distractor to be ignored. Increasing the number of distractors to be ignored on the prime trial might also be considered a manipulation of selection difficulty, as it is presumably more difficult to select a target object from among several competing objects than it is to select the target from just one distracting object. ${ }^{5}$ If this is the case, increased NP might be expected when there are more distractors to be ignored. The results of Yee (1991) are in agreement with this hypothesis. As previously discussed, she found no evidence for NP from ignored words when just one distractor word was presented, while reliable NP was observed when there were two distractor words to be ignored.

However, in a direct investigation of the impact of the number of to be ignored distractors on subsequent NP, Neumann and DeSchepper (1992, Experiment 1) found directly the opposite results. In a letter-naming task, they observed NP of $11 \mathrm{msec}$ with one distracting letter present in the display, which decreased to $7 \mathrm{msec}$ with two distracting letters, and was eliminated when there were three distracting letters in the display. However, because the prime and probe displays always contained the same number of distractors, it is impossible to determine whether the variation in NP was due to the number of distractors on the prime display or whether the results were due to the number of distractors presented on the probe display. In a follow-up study, Neumann, Cherau, Hood, and Steinnagel (1993) found a very similar pattern of results when the number of distractors on the probe display was held constant. Thus, it seems that the number of distractors on the prime display is indeed the critical factor in determining the magnitude of NP. Neumann and DeSchepper (1992) interpreted their results as suggesting that some form of "spreading inhibition" might underlie the suppression of distractors observed in NP tasks. As mentioned previously, Tipper and Driver (1988) found that if subjects ignored a distracting picture, subsequent responses to semantically related words were inhibited. Semantic generalization must be responsible for this NP effect and, from a selective inhibition perspective, it seems plausible to suppose that inhibition might be attached to nodes in some kind of semantic recognition network (e.g., Collins \& Loftus, 1975). Following this logic, Neumann and DeSchepper (1992) argued that inhibition is of limited capacity, analogous to limited capacity spreading-activation (see Anderson, 1983; Collins \& Loftus, 1975). The basic idea is that the rate of response to a target that has just been ignored should be a function of the level of inhibition that its mental representation has undergone. In addition, there should be a dispersion of available inhibition energy among the distractors in a display. Thus, the more distractors there are to be ignored, the less strength of inhibition there should be to any one of them.

To summarize, the research of Neumann and his colleagues (Neumann et al., 1993; Neumann \& DeSchepper, 1992) indicates that when there are a number of distractors in a scene that compete with the target for control of action (e.g., distracting letters in a letteridentification task), three or more distractors do not produce as much NP as one (note the contrast with Yee's [1991] data). This result can be explained by the selective inhibition hypothesis with the assumption that inhibition is of limited capacity, so that one distractor is easier to inhibit than many distractors. Alternatively, this result may be because many distractors cannot be encoded to the same extent as a single distractor, and therefore a single distractor is more likely to be retrieved (Neill, Valdes, Terry, \& Gorfein, 1992). For example, it is possible that when there are many distractors to be ignored, the attentional system may simply shift into an early-selection mode, so that the second and subsequent distracting items are simply not encoded (cf. Lavie \& Tsal, 1994). If this is the case, both the feature mismatching and the episodic retrieval hypotheses can account for reduced NP with more distractors. Neill, Valdes, Terry, and Gorfein (1992) suggest a second possible explanation for this result: When there are more distractors to be ignored, the probability of retrieving the priming episode may be reduced, since the similarity between the prime and probe trials is decreased by the increased number of unrelated distractors in the two trials. Thus, the probe trial would provide a less effective retrieval cue for the priming episode.

\section{The Presence of Distractors on the Probe Trial}

The previous sections illustrate that various manipulations on the prime trial (e.g., target precuing, targetdistractor separation, number of distractors) can influence the amount of NP observed. It has also been established that manipulations on the probe trial may determine whether or not NP is observed. If an ignored repetition probe trial contains a distractor that conflicts with the correct response, NP occurs; if an ignored repetition probe trial does not contain a distractor, NP may not occur. A summary of the relevant studies is provided in Table 3.

The discovery that selection on the probe trial may be critical for NP was made by Lowe (1979). As discussed previously, he found that NP occurred when there was conflict (i.e., a distracting word) on the probe trial, but not when there was no conflict (i.e., a color-patch). A very similar pattern of results has been found with letter naming - viz., facilitation from previously ignored distractors when there is no conflict on the probe trial, and NP from ignored distractors when there is conflict on the probe trial (Allport et al., 1985, Experiment 9; Tipper \& Cranston, 1985, Experiment 3). Similarly, Tipper et al. (1990, Experiment 5) found no NP when there was no 
probe conflict in the target-localization task, while NP did occur when conflict was present on the probe trial (Tipper et al., 1990, Experiment 3a). Taken together, these results indicate that NP is dependent on the presence of a conflicting distractor on the probe trial.

There are a number of experiments, however, that show NP sometimes to be independent of probe-trial conflict. First, Neill and Westberry (1987) required subjects to report the color of letter-string stimuli. Some of the letter strings were nonconflict (e.g., OOOO), and others were conflict color-words (e.g., "blue" printed in red). These conflict and nonconflict trials occurred randomly, and equivalent NP was observed on both types of trials. Similarly, Neill, Terry, and Valdes (1994) presented the target-localization task in which probe trials sometimes included conflict (a distractor) and sometimes did not. These trials were randomized in the experiment and, once again, the magnitude of NP observed was independent of probe-trial conflict.

Thus, a number of studies have shown that NP effects are sensitive to the presence of conflicting information on the probe trial (Allport et al., 1985; Lowe, 1979; Tipper \& Cranston, 1985; Tipper et al., 1990), while other studies have found that NP is independent of probe-trial conflict (Neill et al., 1994; Neill \& Westberry, 1987). In addition, studies using lexical decision on the probe trial have found NP effects even though conflict is never present on the probe trial (Fox, 1994a; Fuentes \& Tudela, 1992 , although the NP effect just failed to reach significance; Yee, 1991; see also Neill, Valdes, \& Terry 1992, Experiment 4, for similar results in a letter-identity task).

In a recent series of studies, Moore (1994) has set out to resolve the apparent inconsistencies of the effects of probe-trial conflict on NP. In an initial experiment, she established that NP does not occur in a letter-identification task when no conflicting distractor is present on the probe trial, while reliable NP was observed when probetrial conflict was present. Interestingly, this pattern occurred whether the conflict and nonconflict trials were presented in separate blocks or were randomiy intermixed. In a second experiment, nonconflict probe trials contained a distracting letter that was not from the response set. Thus, distractors on these trials did not contain information that conflicted directly with the correct response. When conflict and nonconflict trials were randomly intermixed, equivalent NP was observed on conflict and nonconflict probe trials, presumably because subjects could not anticipate when the probe trial might contain conflicting information. In a particularly informative experiment (Moore, Experiment 5), it was shown that NP can occur on nonconflict probe trials that previously showed no NP (i.e., on probe trials in which only a target was presented), as long as those nonconflict probe trials could not easily be identified as nonconflict. The technique was to present the typical nonconflict probe trial containing a single target that was cued by color. However, on some probe trials, rather than a target, a single distractor was presented. On these trials, the subjects were instructed to withhold responding. Thus, they could no longer identify nonconflict trials solely on the basis of a single letter being presented. As shown in Table 3, significant NP was observed on both conflict and nonconflict probe trials under these conditions. Thus, the indication is that NP will fail to occur on nonconflict probe trials only when they can be identified easily as containing no information that might conflict with

Table 3

Summary of Studies Investigating Whether Conflict on the Probe Trial Is a Necessary Condition for Negative Priming to Occur

\begin{tabular}{|c|c|c|c|c|}
\hline Authors & Stimuli & $\begin{array}{c}\text { Probe } \\
\text { Task }\end{array}$ & Conflict & $\begin{array}{l}\text { Priming } \\
\text { (msec) }\end{array}$ \\
\hline Lowe (1979, Exp. 4) & $\begin{array}{l}\text { Color words or } \\
\text { color patches }\end{array}$ & Color naming & $\begin{array}{l}\text { Yes } \\
\text { No }\end{array}$ & $\begin{array}{l}-37 \dagger \\
+22 \dagger\end{array}$ \\
\hline $\begin{array}{l}\text { Allport et al. } \\
\quad(1985, \text { Exp. 9) }\end{array}$ & Letters & Letter naming & $\begin{array}{l}\text { Yes } \\
\text { No }\end{array}$ & $\begin{array}{l}-18 \dagger \\
+13\end{array}$ \\
\hline $\begin{array}{l}\text { Tipper \& Cranston } \\
\text { (1985, Exp. 3) }\end{array}$ & Letters & Letter naming & $\begin{array}{l}\text { Yes } \\
\text { No }\end{array}$ & $\begin{array}{l}-17 \dagger \\
+14^{*}\end{array}$ \\
\hline $\begin{array}{l}\text { Neill \& Westberry } \\
\quad(1987, \text { Exp. } 1)\end{array}$ & Letter strings & Color naming & $\begin{array}{l}\text { Yes } \\
\text { No }\end{array}$ & $\begin{array}{l}-31^{* a} \\
-20^{*}\end{array}$ \\
\hline $\begin{array}{l}\text { Tipper et al. } \\
\text { (1990, Exp. 3a) }\end{array}$ & $O$ and $X$ & $\begin{array}{c}\text { Manually report } \\
\text { location of } O\end{array}$ & $\begin{array}{l}\text { Yes } \\
\text { No }\end{array}$ & $\begin{array}{l}-28 \dagger \\
+1\end{array}$ \\
\hline \multicolumn{5}{|l|}{$\begin{array}{l}\text { Tipper et al. } \\
\text { (1990, Exp. 5) }\end{array}$} \\
\hline Neill et al. (1994) & $O$ and $X$ & $\begin{array}{c}\text { Manually report } \\
\text { location of } O\end{array}$ & $\begin{array}{l}\text { Yes } \\
\text { No }\end{array}$ & $\begin{array}{l}-16^{*} \\
-29+\end{array}$ \\
\hline Moore (1994, Exp. 1) & Letters & $\begin{array}{l}\text { Manually identify } \\
\text { target letter }\end{array}$ & $\begin{array}{l}\text { Yes } \\
\text { No }\end{array}$ & $\begin{array}{c}-60^{* b} \\
0\end{array}$ \\
\hline Moore (1994, Exp. 5) & Letters & $\begin{array}{l}\text { Manually identify target } \\
\text { letter; withhold response } \\
\text { to certain targets }{ }^{\mathrm{c}}\end{array}$ & $\begin{array}{l}\text { Yes } \\
\text { No }\end{array}$ & $\begin{array}{l}-15^{* b} \\
-39 \dagger\end{array}$ \\
\hline
\end{tabular}

Note- "These results are from the "strict accuracy" condition only. bThese effects are estimates. "See text for further details. ${ }^{*} p<.05$. $\dagger p<.01$. 
the correct response. This conclusion is consistent with the results of several previous studies (Allport et al., 1985; Lowe, 1979; Neill et al., 1994; Neill \& Westberry, 1987; Tipper et al., 1990; Tipper \& Cranston, 1985).

As noted previously, however, some results indicate that easily identified nonconflict probe trials are not a sufficient condition for NP to fail to occur (e.g., Fox, 1994a; Yee, 1991). In the studies by both Fox and Yee, a categorization task was required on the prime trial, and then the subjects made a lexical decision to a single letter string on a probe trial. All probe trials were nonconflict, and yet NP was observed. However, in both of these experiments, fairly complex high-level processing was required. Thus, from a selective inhibition perspective, it could be argued that the relative difficulty of the tasks required in these experiments led to the implementation of inhibitory processes, even though no conflict was ever present on probe trials (for an alternative explanation of NP with probe lexical-decision tasks, see May et al., in press). For example, Moore (1994) has argued that the inhibitory process might be engaged by default when task processing is especially demanding. ${ }^{6}$

At first sight, the finding that NP sometimes disappears when there is no distracting information present on the probe trial (Allport et al., 1985; Lowe, 1979; Moore, 1994; Tipper \& Cranston, 1985) would seem to be inconsistent with the selective inhibition hypothesis. If inhibition occurs during the prime trial, manipulations on the probe trial should not affect NP. However, the dependence of NP on probe-trial conflict presents no difficulty for a selective inhibition model that assumes that responses are based on relative, rather than absolute, levels of activation (e.g., Houghton \& Tipper, 1994). According to this type of model, responding is based on the first stimulus representation to become more activated than any other stimulus representation. Thus, responding to a recently ignored item takes longer when conflicting information is present because residual inhibition delays that item's representation from becoming more activated than the probe distractor's representation. In contrast, if no conflicting representation is activated (i.e., if there is no distractor on probe trials), the probe target might already be sufficiently more activated than any other representation, and hence no NP would be observed.

On this basis, Moore (1994) argues that the failure to find NP under some conditions does not necessarily invalidate inhibitory-selection interpretations of NP. Instead, she argues that NP may reflect inhibition of a specific process that only sometimes contributes to RT. If that process is inhibited during the prime trial, NP will only be apparent if that particular process is also involved on the probe trial. If the process is not involved on the probe trial, the inhibition may go unnoticed, and no NP will be observed. This specific-process account of NP (Moore, 1994) implies that the failure to find NP under some conditions may be helpful in identifying which particular process is affected through inhibitory selection.
If NP is due to the retrieval of previous processing episodes cued by processing of the probe trial, the current results might be attributed to changes in contextual similarity between the conflict and no-conflict probe trials and the prime trials. As pointed out by Neill, Valdes, Terry, and Gorfein (1992), the contextual similarity between prime and probe displays should be an important determinant of the probability of retrieval of the priming episode. Thus, retrieval accounts of NP would be supported by a demonstration that decreasing the probability of retrieval of priming episodes also reduces NP. Previous episodes are most likely to be retrieved when the conditions at retrieval are most similar to those at encoding (Tulving \& Thompson, 1973). In the present context, the time of retrieval is during the probe display and the time of encoding is during the prime display. Thus, accurate retrieval of prime-trial information is most likely to be successful when the prime and probe trials are very similar to each other. Unfortunately, there are very little data on this issue. However, the finding that NP sometimes depends on the presence of probe-trial conflict (which is similar to the prime trial) could be construed as support for retrieval-based hypotheses. This suggestion is constrained, however, by the fact that Moore (1994, Experiment 5) also found significant NP under conditions in which the prime and probe displays were dissimilar (i.e., in which the prime display contained a target and a distractor, while the probe trial contained only a target). A study directly investigating the effect of the contextual similarity between prime and probe displays on the magnitude of NP would be a useful test of the notion that NP is due to retrieval, rather than inhibitory, processes.

\section{HOW PERSISTENT IS NEGATIVE PRIMING?}

The previous sections considered a range of factors that can influence the magnitude of NP observed. A separate question concerns how long NP lasts once it has been established: Does NP persist for an indefinite period, or does it decay over time? If NP is a reflection of an inhibitory mechanism that assists in the selection of target objects, it seems unlikely that distracting information would remain inhibited after a response has been made to the prime target (but see May et al., in press, for an alternative possibility). If NP is a reflection of retrieval of a previous processing episode, increasing the time lag between prime and probe displays might be expected to decrease the magnitude of observed NP because of a decaying memory function. A number of studies have investigated the persistence of NP by manipulating the response-to-stimulus interval (RSI), which is the time between responding to a prime target and the onset of the probe stimulus. A summary of studies that examined NP as a function of RSI is shown in Table 4. Neill and Westberry (1987) were the first to look at this issue. They presented a color-naming task (stimuli were either color-words or strings of $O$ s), and randomly varied the RSI. As shown in Table 4, there was an inter- 
action between RSI and NP, whereby NP occurred at RSIs of 20, 520, and $1,020 \mathrm{msec}$, but no NP was apparent at an RSI of 2,020 msec. Neill and Westberry (1987) concluded that NP persists for about $1 \mathrm{sec}$, but then dissipates completely by about $2 \mathrm{sec}$.

Subsequent research, however, indicates that NP may persist for much longer than $2 \mathrm{sec}$. First, Tipper, Weaver, Cameron, et al. (1991, Experiment 1) manipulated the RSI as a between-subjects factor, and found no dissipation of NP across increasing RSIs. In this study, a target picture was presented at fixation, with a distractor appearing randomly $2.58^{\circ}$ of visual angle to the right or the left. Following the subject's response, there was an RSI of $1,350,3,100$, or $6,600 \mathrm{msec}$ before the presentation of the next stimulus. NP was found at all three RSIs, in contrast to Neill and Westberry's (1987) results. As shown in Table 4 , the absence of any RSI $\times$ NP interaction was true both for picture-naming tasks and for targetlocalization tasks (Tipper, Weaver, Cameron, et al., 1991, Experiment 3). In these experiments, then, NP is still apparent even with an RSI of almost $7 \mathrm{sec}$. Hasher et al. (1991) also manipulated RSI as a between-subjects factor (actually, between experiments) and, for young subjects, found very similar levels of NP at RSIs of 500 and $1,200 \mathrm{msec}$.

Neill and Valdes (1992) speculated that the failure of Tipper, Weaver, Cameron, et al. (1991) and Hasher et al. (1991) to find a decay in NP at relatively long RSIs might have been due to the use of a between-subjects design with relatively low statistical power. In particular, since Tipper, Weaver, Cameron, et al. used only very long RSIs (i.e., minimum RSI was $1,350 \mathrm{msec}$ ), it is possible that any decay effects may have been too small to detect. This is a plausible assumption, given that decay effects are more pronounced at short intervals than at long intervals. To investigate this hypothesis, Neill and Valdes (1992) presented the letter-matching procedure developed by Neill et al. (1990), randomly presenting RSIs of $500,1,000,2,000,4,000$, and $8,000 \mathrm{msec}$ in a within-subjects design. An overall NP effect of $24 \mathrm{msec}$ was observed, which interacted significantly with RSI, such that the magnitude of NP decreased from about $70 \mathrm{msec}$ at an RSI of $500 \mathrm{msec}$ to about $8 \mathrm{msec}$ at an RSI of $8,000 \mathrm{msec}$. It should be remembered that this NP effect cannot be attributed to feature mismatching, as the degree of mismatch between prime and probe displays is similar for control and ignored repetition probe trials. The decay in NP was most pronounced between 500 and 1,000 msec RSI. When the data from the 500msec RSI were eliminated from the analysis, there was still a significant NP effect, but there was now no NP $\times$ RSI interaction, a finding that is very similar to that reported by Tipper, Weaver, Cameron, et al.

In subsequent studies, Neill, Valdes, Terry, and Gorfein (1992) have established that NP also decays with increasing RSI in the target-localization task. They noted that when RSI is manipulated between subjects (e.g., Hasher et al., 1991; Tipper, Weaver, Cameron, et al., 1991), the RSI between the prime and probe displays is necessarily confounded with delays prior to the prime display, and this might explain the absence of decay. In support of this, Neill, Valdes, Terry, and Gorfein discovered that when the preceding RSI (PRSI) and the RSI were equated, equivalent NP was observed whether the RSI was 500 or $4,000 \mathrm{msec}$ (i.e., there was no decay). In a separate experiment, it was shown that when the PRSI

Table 4

Summary of Studies Investigating the Persistence of Negative Priming by Manipulating the RSI

\begin{tabular}{|c|c|c|c|c|c|}
\hline Authors & Probe Task & Design & RSI & $\begin{array}{c}\text { Priming } \\
\text { (msec) }\end{array}$ & Interaction \\
\hline $\begin{array}{l}\text { Neill \& Westberry } \\
\text { (1987, Exp. 2) }\end{array}$ & Color naming & Within subjects & $\begin{array}{r}20 \\
520 \\
1,020 \\
2,020\end{array}$ & $\begin{array}{r}-18 \\
-26 \\
-11 \\
+5\end{array}$ & $p<.05$ \\
\hline $\begin{array}{l}\text { Tipper, Weaver, } \\
\text { Cameron, et al. } \\
\text { (1991, Exp. 1) }\end{array}$ & Picture naming & Between subjects & $\begin{array}{l}1,350 \\
3,100 \\
6,600\end{array}$ & $\begin{array}{l}-10 \\
-10 \\
-22\end{array}$ & n.s. \\
\hline $\begin{array}{l}\text { Tipper, Weaver, } \\
\text { Cameron et al. } \\
\text { (1991, Exp. 3) }\end{array}$ & Localization & Between subjects & $\begin{array}{l}1,350 \\
3,100 \\
6,600\end{array}$ & $\begin{array}{r}-11 \\
-6 \\
-14\end{array}$ & n.s. \\
\hline Hasher et al. (1991) & Letter naming & Between subjects & $\begin{array}{r}500 \\
1,200\end{array}$ & $\begin{array}{r}-8.9 \\
-7.5\end{array}$ & n.s. \\
\hline $\begin{array}{l}\text { Neill \& Valdes } \\
\quad(1992, \text { Exp. 1) }\end{array}$ & Letter matching & Within subjects & $\begin{array}{r}500 \\
1,000 \\
2,000 \\
4,000 \\
8,000\end{array}$ & $\begin{array}{r}-72^{\circ} \\
-15 \\
-35 \\
+4 \\
-4\end{array}$ & $p<.001$ \\
\hline $\begin{array}{l}\text { Neill, Valdes, Terry, } \\
\text { \& Gorfein } \\
\text { (1992, Exp. 1) }\end{array}$ & Localization & Within subjects & $\begin{array}{r}500 \\
4,000\end{array}$ & $\begin{array}{l}-32 \\
-17\end{array}$ & $p<.01$ \\
\hline
\end{tabular}

Note-Also shown is (1) type of task; (2) whether RSI was manipulated between or within subjects; (3) the RSI; (4) the magnitude of priming observed; and (5) the significance level of the RSI $\times$ priming interaction. "These effects are estimates. 
and RSI were deliberately confounded by being presented in separate blocks (within subjects), there was still no interaction between NP and RSI (Neill, Valdes, Terry, \& Gorfein, Experiment 2). More important, however, was the finding that NP effects did decay over RSI when the RSI was randomized across trials (Neill, Valdes, Terry, \& Gorfein, Experiment 1): When the PRSI was $4,000 \mathrm{msec}$ and the RSI was $500 \mathrm{msec}$, the greatest magnitude of NP was observed, while the lowest magnitude was observed when the PRSI was $500 \mathrm{msec}$ and the RSI was $4,000 \mathrm{msec}$. These results go some way toward reconciling the conflicting results concerning RSI and decay of NP. It seems clear that NP decays over RSI when the RSI is randomized over trials (Neill \& Valdes, 1992; Neill, Valdes, Terry, \& Gorfein, 1992; Neill \& Westberry, 1987), but does not decay when the RSI is held constant (Hasher et al, 1991; Neill, Valdes, Terry, \& Gorfein, 1992, Experiment 2; Tipper, Weaver, Cameron, et al., 1991).

It is of particular interest that NP is dependent on the delay prior to the prime display. If it is the case that distracting information is inhibited during (prime-) target selection and that this inhibition then passively decays, it is not at all clear why the delay before the prime trial should be critical. Thus, the current results present serious problems for the selective inhibition hypothesis. On the other hand, the episodic retrieval account attributes NP to the backward retrieval of previous priming episodes cued by the processing of the probe display. On this view, factors that affect the probability of retrieving the priming episode would have a critical impact on NP. One potent factor is the temporal delay between the prime and the probe: The shorter the delay, the greater the probability of retrieval and the greater the magnitude of NP. Significant decay of NP over increasing RSI is consistent with this (Neill \& Valdes, 1992; Neill, Valdes, Terry, \& Gorfein, 1992; Neill \& Westberry, 1987). A second factor is the discriminability of processing episodes: If the priming episode is easy to discriminate from preceding episodes, the probability of retrieval increases, and hence robust NP is observed. Persistence of NP over long RSIs, when the delay between the prime and probe displays and the delay preceding the prime display are equated, is consistent with this (Hasher et al., 1991; Neill, Valdes, Terry, \& Gorfein, 1992; Tipper, Weaver, Cameron, et al., 1991). Neill et al. (in press) have argued that discriminability is most critical when stimuli are used repeatedly as both targets and distractors over the course of an experiment. Under these conditions, a previous episode containing the current target as an ignored distractor must compete with other episodes in which the item appeared as a target. If an item has appeared only once in an experiment, that episode has a high probability of retrieval, and thus should produce substantial NP. However, if an item has appeared many times, the probability of retrieval is reduced, and the level of NP should also be reduced. The data on this issue are scarce, although the results reported by DeSchepper and Treisman (1991) provide some support, in that they found reliable NP from ignored nonsense shapes that appeared only twice in an experiment (once as a prime distractor and once as a probe target). Of particular interest is their finding that the magnitude of NP was significantly reduced when items were repeated over and over, relative to when they were presented only once ( $31 \mathrm{vs.} 55 \mathrm{msec}$, respectively), as is predicted by the episodic retrieval hypothesis (DeSchepper \& Treisman, Experiment 2). On the other hand, however, Malley and Strayer (in press) have found directly the opposite results with more familiar stimuli in a word-naming task; they found identity NP from ignored words only when those words had been repeated many times. Words that had been presented only twice (once as a prime distractor and once as a probe target) produced no identity NP. Clearly, the dependence (or otherwise) of NP on stimulus repetition and/or stimulus novelty requires further investigation.

\section{CAN NEGATIVE PRIMING SURVIVE OVER MANY TRIALS ?}

An interesting question concerns whether NP still occurs if the ignored item is presented as a target several trials later. DeSchepper and Treisman's (1991) experiments with nonsense shapes give some indication that this may be the case. They found very strong NP effects from ignored shapes that had been presented only twice. The authors argued that even a single exposure of an ignored item can set up a temporary representation (i.e., an object token, Kahneman \& Treisman, 1984) that mediates its future perception. These object tokens for ignored items may survive in memory across many trials, so that the response to them is still delayed if they subsequently become relevant many trials later (see DeSchepper \& Treisman, 1991; Treisman, 1992; but see Malley \& Strayer, in press). The persistence of NP across many trials is compatible with the episodic retrieval account of NP because the probability of retrieving an item that has been presented only once is high even if many trials intervene. However, from a selective inhibition perspective, this finding is more difficult to explain. It is also difficult to reconcile with the feature mismatching hypothesis that assumes that NP is due to a mismatch between individual prime and probe trials. It should be noted, however, that the stimuli used by DeSchepper and Treisman may not have been truly novel. For example, Malley and Strayer have argued that since the nonsense shapes were very similar to each other, it is possible that subjects may have developed a prototypic representation of these shapes. If this were the case, the repetition of highly similar shapes may be analogous to the repetition of a limited number of stimuli many times during an experiment that generally tends to occur in other NP studies.

Another approach is to investigate whether NP can survive the processing of an intervening event between prime and probe displays. Experiments by Tipper, Weaver, Cameron, et al. (1991, Experiments 2 and 6) in- 
dicate that NP can survive intervening events unless either the intervening event is a novel one (i.e., has a low probability) or the ignored stimulus itself appears as a target item between the prime and probe displays. If NP is caused by selective inhibition applied during the prime trial, it is unclear why the presentation of a lowprobability stimulus, as opposed to a high-probability event, should reduce the magnitude of NP. As pointed out by Neill, Valdes, Terry, and Gorfein (1992), however, it may be that a surprising event changes the retrieval context, reducing the likelihood that the previous prime trial will be retrieved. Thus, both the feature mismatching and episodic retrieval hypotheses can account for this result.

\section{INDIVIDUAL DIFFERENCES IN NEGATIVE PRIMING}

One of the reasons for the current interest in the NP paradigm is the finding that individuals with cognitive deficits frequently fail to show significant NP effects. This is a rapidly expanding literature, and no attempt is made here to provide a comprehensive review (see May et al., in press, for a more extensive discussion). Instead, some representative studies using standard NP techniques will be discussed. The cognitive failures questionnaire (CFQ: Broadbent, Cooper, Fitzgerald, \& Parkes, 1982) is assumed to provide a self-report measure of everyday lapses of selective attention, and includes such questions as "Do you fail to notice signposts on the road?" In the experiments reported by Tipper and Baylis (1987), the subjects were divided into two groups on the basis of their scores on the CFQ. In the first experiment, the subjects named the category of a target word that was sometimes accompanied by a distracting word. The amount of flanker interference due to the presence of a distracting word was much larger in the group with high CFQ scores $(71 \mathrm{msec})$ than it was in the group with low CFQ scores $(30 \mathrm{msec})$. In a second experiment, it was found that the subjects who scored low on the CFQ showed significant identity NP, while those who scored high showed a nonsignificant trend toward positive identity priming. Neither group showed any semantic NP. The authors argue that these results suggest that individuals who are prone to cognitive failures show deficits in the ability to inhibit distracting information. An alternative possibility, of course, is that individuals who are prone to cognitive failures suffer deficits in the ability to retrieve previous processing episodes. Thus, these results cannot shed light on the question of whether NP is caused by selective inhibition during the prime display or by feature mismatching or episodic retrieval cued by the probe display.

The elderly comprise another group of subjects who are often prone to cognitive failures. One theoretical development in this area is the notion that many of these deficits might be due to reduced inhibitory function in older age. For example, it has been stated that "the increased presence of irrelevant thoughts in working mem- ory (and the attendant consequences) may well be the factors that produce the behaviors that have made it appear as if older adults have reduced capacity for cognitive functions" (Hasher \& Zacks, 1988, p. 216). As mentioned in a previous section, there is substantial evidence that older adults show diminished NP relative to younger adults in target-identity tasks (e.g., Connelly \& Hasher, 1993; Hasher et al., 1991; McDowd \& Oseas-Kreger, 1991; Tipper, 1991), but not in target-localization tasks (Connelly \& Hasher). A very similar pattern has been found for children, who, when very young, show no NP toward the identity of distractor objects; this NP does, however, develop with age (Tipper et al., 1989). In contrast, even quite young children show reliable NP toward the locations of distracting objects (Tipper \& McLaren, 1990). From a selective inhibition perspective, this pattern of results in both young and old subjects suggests that inhibition of spatial locations may be a "first-in, last-out" process (i.e., it is present at an early age and still apparent in old age), while inhibition of object identities may be a "last-in, first-out" process (i.e., it is not present at a very young age and is easily disrupted in old age). On the other hand, this pattern of results might indicate that young children and old adults suffer from feature mismatching rather than from a breakdown in an inhibitory system. Recall that feature mismatching is more likely to produce NP in target-localization tasks than in target-identification tasks (see Milliken et al., 1994; Park \& Kanwisher, 1994; Tipper \& Cranston, 1985). While clearly speculative, it might be the case that older adults (and children) make greater use of matching previous episodes to assist a slower-than-normal cognitive system. If this is the case, individual differences would be less apparent in localization tasks (in which feature mismatching is important) than in identification tasks (in which feature mismatching is less important). Another alternative is that the pattern of individual differences may indicate that young and old people show a deficit in the implicit retrieval of the identities of previously ignored items, but not in the retrieval of their locations. As with the selective inhibition account, it may be the case that the retrieval of information about the locations occupied by objects is a first-in, last-out process, whereas the retrieval of information about object identities may be a last-in, first-out process. While these suggestions are clearly speculative, it is worth noting that the failure to find NP in various subgroups is almost universally interpreted as a deficit in an inhibitory mechanism. The feature mismatching and episodic retrieval hypotheses raise the possibility that these subgroups may in fact have a deficit in retrieval mechanisms rather than in inhibitory mechanisms (see May et al., in press for further discussion).

Deficits in the effective inhibition of distracting information have also been implicated in the development and maintenance of a number of psychological disorders, such as schizophrenia (e.g., Frith, 1979), obsessive-compulsive disorder (Enright \& Beech, 1990; Enright \& Beech, 1993a, 1993b), and anxiety (Fox, 1994a). Most of the em- 
pirical work has been conducted with schizophrenia. For example, Beech, Powell, McWilliam, and Claridge (1989) found that people with schizophrenia show diminished NP in comparison with a group of matched controls. Furthermore, university students who obtain high scores on questionnaire measures of schizophreniclike symptoms tend to show increased flanker interference from ignored distractors, but reduced NP relative to those with low scores on the same questionnaires (Beech, Baylis, et al., 1989; Beech \& Claridge, 1987; Beech et al., 1991). Once again, it should be noted that these results may indicate problems with retrieval mechanisms rather than with inhibitory mechanisms.

Apart from a variety of psychological disorders, lowerthan-usual levels of NP are also associated with poor comprehension of written text. In a series of experiments, Gernsbacher and Faust (1991) found that less skilled comprehenders experienced more disruption from irrelevant information and showed less NP than did more skilled comprehenders. The authors suggest that the poor comprehenders may be less able to inhibit distracting material than good comprehenders. An alternative interpretation is that poor comprehenders are less able to retrieve previous processing episodes.

Taken together, the results discussed in this section suggest that the magnitude of NP from ignored distractors is reduced in a variety of subgroups (e.g., young children, older adults, schizophrenics). The most widespread interpretation of this result is that the ability to suppress irrelevant information is critical in maintaining effective cognitive functioning. If this inhibitory system becomes compromised, a variety of cognitive deficits and lapses are likely to follow (e.g., Hasher et al, 1991; McDowd \& Oseas-Kreger, 1991; Tipper \& Baylis, 1987). This interpretation is, of course, dependent on the selective inhibition theory of NP. If it is the case that NP is actually caused by feature mismatching and/or episodic retrieval of previously ignored items, these theoretical views will need to be reappraised. Whatever the cause of NP, however, the work discussed in this section indicates that NP (or at least the mechanism it reflects) probably has adaptive consequences for behavior (Neill et al., in press).

\section{SUMMARY}

To recapitulate, NP appears to be a robust effect that has been demonstrated across a range of stimuli (words, letters, drawings, numbers, and nonsense shapes) and across a variety of task demands (categorization, matching, counting, and localization). Having said this, however, it is clear that the magnitude of NP is generally quite small (e.g., less than $20 \mathrm{msec}$ is common) and that semantic (but not identity) NP is very inconsistent when words are used as stimuli. Further, for some of the issues discussed, the data appear to be in conflict. For example, in some studies, probe-trial conflict is critical for NP (e.g., Lowe, 1979), whereas in others, it is not (e.g., Neill \& Westberry, 1987). Nevertheless, the following findings have been fairly well established, and any comprehensive theory of NP would need to account for them.

1. It is clear that NP can be associated with any perceptual feature of an ignored object (e.g., color, location, identity) and that it is apparently flexible, depending on the behavioral goals of the task (Milliken et al., 1994; Tipper et al., 1994).

2. The magnitude of NP (sometimes) increases with increased selection difficulty and/or increased flanker interference during the prime trial (DeSchepper \& Treisman, 1991; Fox, 1994b; Milliken et al., 1994; Neill \& Lissner, 1988; Valdes, 1993, cited in Neill et al., in press).

3 . It has also been shown that NP is frequently independent of flanker-interference effects (Allport et al., 1985; Beech, Agar, \& Baylis, 1989; Driver \& Tipper, 1989; Fox, 1995; Tipper, Weaver, Kirkpatrick, \& Lewis, 1991).

4. The magnitude of NP decreases as the number of objects to be ignored increases (Neumann et al., 1993; Neumann \& DeSchepper, 1992; but see Yee, 1991, for contrasting results).

5. NP sometimes depends on the presence (or on the anticipation) of distracting stimuli on the probe trial (see Moore, 1994).

6. NP requires time to develop (Allport et al., 1985; Neill \& Westberry, 1987; Neumann \& DeSchepper, 1992; Yee, 1991), dissipates over time after it is established (Neill \& Valdes, 1992; Neill, Valdes, Terry, \& Gorfein, 1992), and is dependent on the delay prior to the prime trial (Neill, Valdes, Terry, \& Gorfein).

7 . Under some circumstances, NP can survive the processing of an intervening event between prime and probe displays (Tipper, Weaver, Cameron, et al., 1991, Experiments 2 and 6; see also Malley \& Strayer, in press).

8. At least under some conditions, NP does not seem to require any preexisting mental representations or familiarity (DeSchepper \& Treisman, 1991; but see Malley $\&$ Strayer, in press, for alternative results), and there is some indication that NP may last over several trials (DeSchepper \& Treisman, 1991; Tipper, Weaver, Cameron, et al., 1991).

The basic phenomenon to be explained is why people are impaired in responding to an item they have recently ignored. As should be clear from the foregoing review, the literature on NP is rather disparate, and it is difficult to draw many firm conclusions about what might cause it. It is far too early to decide between selective inhibition, feature mismatching, and episodic retrieval accounts, in terms of explanation of the NP effect. Substantially more empirical data are required before such a distinction can be made. Such a distinction is of critical importance, however, on both theoretical and practical grounds. Theoretically, it is important to establish whether NP is telling us something about the mechanisms underlying visual selective attention, those underlying the automatic retrieval of previous processing episodes, or both. Given the clear individual differences that have been found in NP, it is also of practical impor- 
tance to establish whether these differences are due to a failure to inhibit irrelevant processing or whether they are due to a failure to adequately encode or retrieve ignored information. This final section of the paper summarizes the strength of the overall evidence for and against each of the three main accounts of the NP effect. A summary of the evidence for and against each of the three accounts is provided in Table 5, which includes only those empirical phenomena that cannot be explained equally well by each of the theories. As discussed below, a range of phenomena can be explained by all three theories.

\section{Evidence For Selective Inhibition}

Selective inhibition theory (e.g., Houghton \& Tipper, 1994; Neumann \& DeSchepper, 1992) proposes that the selective inhibition of distracting information is one of the mechanisms that allows for efficient selection of target objects from distracting objects. As the foregoing review has shown, many of findings in the NP paradigm have been interpreted as supporting the existence of inhibitory mechanisms in visual selection. These findings are as follows:

(1) When subjects are required to respond to recently ignored stimuli, their responses are usually slower and less accurate than their responses to new stimuli. In other words, the NP effect itself is predicted by the hypothesis that target selection occurs-at least in part-through the selective inhibition of the processing of ignored stimuli. (2) Short SOAs between stimulus displays and a pattern mask produce PP, and this reverses to NP with longer display-mask SOAs (Allport et al., 1985; Neill et al., in press). This pattern of results indicates that ignored material is initially activated and that, given sufficient time, further processing of ignored stimuli is inhibited. (3) The finding that individuals who are prone to heightened dis- tractibility also show less NP (e.g., Beech, Powell, et al., 1989; Hasher et al., 1991; Tipper, 1991; Tipper \& Baylis, 1987) supports the notion that the suppression of unwanted information may be an important component of efficient selection. (4) The finding that NP sometimes increases in magnitude when target selection is more difficult (Fox, 1994b; Milliken et al., 1994; Valdes, 1993, cited in Neill et al., in press) again suggests that the suppression of irrelevant processing may be a critical component of efficient selection. (5) There is some neurophysiological evidence that suggests inhibitory processes in selective attention (see Houghton \& Tipper, 1994; Posner \& Driver, 1992, for further discussion); for example, singlecell recording studies show that the neural activity generated by a distractor stimulus may be internally suppressed. Investigations of neural activity in Area V4 and infero-temporal areas of monkey visual cortex have found that cells in these areas respond vigorously when a particular type of stimulus falls within their receptive fields. However, firing rates are strongly suppressed when the same stimulus appears as an ignored distractor (e.g., Chelazzi, Miller, Duncan, \& Desimone, 1993; Moran \& Desimone, 1985). These findings indicate that inhibitory mechanisms may be a critical part of the process of visual selection.

\section{Evidence Against Selective Inhibition}

Most of the foregoing results, while consistent with the selective inhibition hypothesis, can be accounted for without assuming any form of distractor inhibition. These results (with the possible exception of the neurophysiological data) therefore cannot provide strong evidence either for or against the notion of selective inhibition. Moreover, there are two pieces of evidence, both from the target-localization task, that provide evidence

Table 5

Summary of the Empirical Evidence For and Against Each of the Three Theories of NP

Evidence For Theory

Evidence Against Theory

Selective Inhibition

Short SOAs between stimulus displays and pattern mask produce PP; longer SOAs produce NP.

Inverse relation between flanker interference and NP in individual-difference studies.
Mismatches across prime and probe displays can cause NP even when the probe target was not previously ignored.

Ignored prime distractors produce facilitation when there is no mismatch across prime and probe displays. The delay prior to the prime display is critical for NP.

Feature Mismatching

NP occurs when the probe target differs from the item that occupied its position in the prime display, independently of whether the prime item was a target or a distractor. NP can occur when the prime distractor and the probe target are identical (in terms of identity, color, and location).

Ignored prime distractors can produce facilitation (and not NP) NP can occur on tasks in which the degree of mismatch when there is no mismatch across prime and probe displays. is equated for control and ignored repetition trials.

Episodic Retrieval

The persistence of NP depends on the discriminability of the priming episode.

Delays prior to the prime trial are critical to NP.
Mismatches across prime and probe displays can cause NP even when the probe target was not previously ignored.

Ignored words only produce identity NP if they are repeated over and over during an experiment.

Note-Only those phenomena that cannot be explained by all three theories equally are included here. See text for further details. 
against the selective inhibition hypothesis. First, Park and Kanwisher (1994) demonstrated that when the probe target was the same symbol that appeared in the same location in the prime display, facilitation occurred. Since the probe target had previously been an ignored distractor, this result effectively rules out the selective inhibition hypothesis (as well as the episodic retrieval hypothesis). In addition, when the probe target was a different symbol from the one that appeared in that location in the prime display, reliable NP occurred, even though both prime items were targets. Further, Park and Kanwisher (Experiment 5) also found facilitation from a match and NP from a mismatch between the prime and probe displays, even when no task at all was required in the prime display. None of these results can be easily explained by the selective inhibition account, since it assumes that NP is caused by the necessity of responding to a target that was recently ignored.

Perhaps the most persuasive evidence against a selective inhibition account of NP is the apparent dependence of NP on the similarity of the RSI between the prime and probe displays and the RSI preceding the prime display (Neill, Valdes, Terry, \& Gorfein, 1992). If NP is indeed due to active inhibition of distracting information applied during the prime trial, it is difficult to explain why the delay before the prime trial should have any influence on the magnitude of the subsequent NP.

\section{Evidence For Feature Mismatching}

It is possible that it is a lack of correspondence between the features of an ignored prime item and those of a subsequent probe target that causes the NP effect. This mismatching hypothesis holds that NP is caused by a change in the bindings of symbol identities (to objects or locations) between prime and probe trials, irrespective of whether the prime symbol is a target or a distractor (Park \& Kanwisher, 1994). In the target-localization task, for example, this notion proposes that NP will occur when the probe target differs from the items that occupied its position in the prime display, independent of whether that prime item was a distractor or a target. The most compelling evidence for the feature mismatching account of NP comes from the target-localization task (Park \& Kanwisher), as discussed in the preceding section.

\section{Evidence Against Feature Mismatching}

Feature mismatching cannot explain NP effects under conditions in which the prime distractor is identical to the probe target. There have been two reported cases of NP occurring under these conditions. First, in a task requiring the naming of letter identities cued by color, Tipper and Cranston (1985) reported significant NP even when the prime distractor (e.g., a red $A$ ) was identical in terms of both color and identity to the probe target (i.e., also a red $A$ ). This result effectively disconfirms the feature mismatching account. Second, in a variant of the target-localization task, Milliken et al. (1994) found that NP occurred even when the prime distractor and probe target were identical in terms of identity, color, and lo- cation (but only when a color cue was presented simultaneously with the prime and the probe displays). Once again, this result cannot be explained by the feature mismatching account of NP.

In addition, NP has been observed in a number of paradigms in which the degree of mismatch in control and ignored repetition trials was equivalent (e.g., Fox, 1994b; Neill et al., 1990; Tipper et al., 1988). NP in these paradigms must, therefore, be caused by something other than feature mismatching across prime and probe displays.

\section{Evidence For Episodic Retrieval}

The episodic retrieval account of NP also attributes it to the implicit retrieval of previous processing episodes. However, this account is fundamentally different from the feature mismatching account, in that it explicitly argues that the current (probe) target's previous role as a distractor is critical to the NP effect. Thus, many of the studies in which the mismatch was equated across control and ignored repetition trials can be accommodated by this account. The episodic retrieval theory of NP extends Logan's (1988) theory of automaticity to situations in which previously ignored information is retrieved. In this sense, the episodic retrieval account is somewhat similar to the selective inhibition account, in that it assumes that the necessity of responding to previously ignored information is critical for NP.

The primary evidence for the episodic retrieval theory is that the persistence of NP depends on the RSI between the prime and probe display being similar to the RSI immediately preceding the prime trial (Neill, Valdes, Terry, \& Gorfein, 1992). This finding indicates that the temporal discriminability of the priming episode is critical to NP, and suggests that NP is due to the retrieval of the processing episode in which the current target was ignored. This is based on the assumption that when retention intervals are blocked, discriminating between successive episodes is constant, regardless of the retention interval (e.g., Baddeley, 1976). In the NP paradigm, the probability of retrieving an episode in which the current probe target had been previously ignored may be constant if RSI is manipulated between subjects or in separate blocks of trials (Neill, Valdes, Terry, \& Gorfein). A decay function may only emerge if RSI is randomly intermixed across trials. This is exactly the pattern that has been found in studies investigating decay effects over RSI (see Table 4). According to the episodic retrieval hypothesis, long-term persistence of NP reflects the relative permanence of processing episodes in memory, but the probability of retrieving such episodes may still decline with increasing RSI.

The episodic retrieval hypothesis predicts that the greatest magnitude of NP should occur at a short RSI that is preceded by a long RSI, since the priming episode is relatively recent and competition from previous episodes is reduced. In contrast, a lower magnitude of NP is expected at a long RSI that is immediately preceded by a short RSI, since in this case, there is increased competition from previous episodes and the priming episode is 
more distant. The pattern of data reported by Neill, Valdes, Terry, and Gorfein (1992) conforms to these predictions, providing strong support for the episodic retrieval hypothesis. In contrast, it is difficult to see how either the feature mismatching hypothesis or the selective inhibition hypothesis can account for this pattern of results.

As well as temporal separation and discriminability, the contextual similarities between prime and probe displays should also be an important determinant of the probability of retrieval of the priming episode. Unfortunately, however, there are no data directly relating to this issue.

\section{Evidence Against Episodic Retrieval}

Since the episodic retrieval account of NP is fairly recent, there have been no direct attempts to disprove it. However, some of the evidence reviewed here is inconsistent with this hypothesis. First, the finding of Park and Kanwisher (1994) showing that feature mismatching can cause NP even when the probe target was not previously ignored is not consistent with the episodic retrieval hypothesis. Second, some difficulty is presented for an episodic retrieval account of NP by the finding that, under some conditions (e.g., speed stress, rapid pattern masking of prime distractors), ignored distractors produce facilitation on the probe trial. If NP is caused by the retrieval of an item that is associated with a nonresponse, which conflicts with the current response, how can ignored distractors produce PP? However, as pointed out previously, the theory may be able to accommodate this facilitation if it assumes priming from perseverative activation. Third, the results of Malley and Strayer (in press) are not consistent with predictions from the episodic retrieval hypothesis. To illustrate, since the probability of retrieving a novel stimulus should be higher than the probability of retrieving a highly activated stimulus, the episodic retrieval hypothesis would predict a greater magnitude of NP with novel stimuli. However, in a direct manipulation of stimulus repetition with word stimuli, Malley and Strayer found the opposite results.

\section{CONCLUSION}

In conclusion, none of the three accounts of NP can provide a complete explanation for all of the extant data. In some limited tasks (e.g., target localization), feature mismatching between prime and probe displays can cause an NP effect (Park \& Kanwisher, 1994), although it is not a necessary condition for NP (Milliken et al., 1994). In a wider range of tasks, NP occurs when subjects are required to respond to previously ignored items (e.g., Milliken et al., 1994; Neill et al., 1990; Tipper \& Cranston, 1985; Tipper et al., 1988), even when they are identical to the current target (i.e., even when there is no mismatch; Milliken et al., 1994; Tipper \& Cranston, 1985). The challenge for future research is to establish whether this effect is due to selective inhibition applied during the prime trial or whether it results from the episodic retrieval of previously ignored stimuli cued by the current processing episode (i.e., the probe trial). It is also, of course, quite possible that NP is codetermined by processing in both prime and probe displays, so that both inhibitory and retrieval processes may interact to produce it (e.g., Milliken et al., 1994).

Both the selective inhibition and episodic retrieval explanations of NP have a high degree of psychobiological plausibility. On the one hand, NP may reflect the suppression of distracting information during target selection, thus allowing for uninterrupted behavioral actions. On the other hand, it may reflect the operation of the retrieval of a previously encountered instance or episode, which helps to allow the development of rapid reactions to environmental stimuli to occur. Either way, the clear individual differences that have been demonstrated suggest that NP has adaptive consequences for future processing. It is therefore of particular importance for research to identify the mechanism that underlies NP. On the one hand, the individual differences that have been observed may reflect differences in inhibitory mechanisms of selective attention. On the other hand, the individual differences may be due to differences in the efficiency of retrieval processes. This issue is therefore an important focus for future research in this area. One of the aims of the current review was to determine whether the phenomenon of NP provides compelling evidence for the inhibition of distracting objects during visual selection. As should be clear by now, while much of the empirical evidence is certainly consistent with such inhibition, almost all of the NP priming results can be explained without recourse to inhibitory mechanisms. It must therefore be concluded that the evidence for selective inhibition in NP tasks is not conclusive (for an alternative conclusion, see May et al., in press). An important focus for future research would be an attempt to provide converging evidence for inhibitory mechanisms from other paradigms.

Newell (1990) has argued that regularities in immediate-response performance are particularly important for cognitive theory, since this is the level closest to the architecture of cognition "where the mind's work shows through" (p. 25). The robustness and regularity of NP effects across a range of experimental situations suggests that NP may reflect a fundamental mechanism or constraint of human information processing. As such, a theoretical understanding of NP could provide a useful focal point for cognitive psychology.

First, NP provides an ideal means with which to study the relation between attention and memory (e.g., Neumann \& DeSchepper, 1992; Treisman, 1992), two areas that are often not considered together at the empirical level. In particular, an important new theory of information processing, the instance theory (Logan, 1988), seems to be capable of accounting for a broad range of cognitive phenomena, such as episodic memory, semantic memory, automaticity, judgment, repetition priming (see Logan, 1988, 1990), and now, NP (Neill, Valdes, Terry, \& Gorfein, 1992). Thus, NP effects can be incorporated into a more general theoretical framework. In particular, 
the coexistence of distractor inhibition and episodic retrieval processes may explain the apparently effortless performance of humans in situations that require a series of selective actions (Milliken et al., 1994). Second, NP is of relevance to investigators in both clinical psychology and neuropsychology, since it provides an objective measure of cognitive functioning that seems to reliably differentiate groups of subjects differing in their degree of cognitive functioning. Neill, Valdes, Terry, and Gorfein suggest that NP is a unique indicator of individual differences, because it is a performance deficit (i.e., more errors or slower RTs) that is associated with normal cognitive functioning. Therefore, diminished NP cannot easily be attributed to a more general slowing of cognitive processing. In conclusion, given that attention can determine the course of many other cognitive processes (see Neill, 1989), an advance in the theoretical understanding of NP is likely to provide an important step toward a more comprehensive understanding of human cognition.

\section{REFERENCES}

Allport, D. A. (1989). Visual attention. In M. I. Posner (Ed.), Foundations of cognitive science (pp. 631-682). Cambridge, MA: MIT Press.

AllPORT, D. A. (1993). Attention and control: Have we been asking the wrong questions? A critical review of 25 years. In D. E. Meyer \& S. Kornblum (Eds.), Attention and performance XIV: A silver jubilee (pp. 183-218). Hillsdale, NJ: Erlbaum.

Allport, D. A., TipPeR, S. P., \& ChMiel, N. R. J. (1985). Perceptual integration and postcategorical filtering. In M. I. Posner \& O. S. M. Marin (Eds.), Attention and performance XI (pp. 107-132). Hillsdale, NJ: Erlbaum.

ANDERSON, J. R. (1983). The architecture of cognition. Cambridge, MA: Harvard University Press.

BADDELEY, A. D. (1976). The psychology of memory. New York: Basic Books.

BeECH, A., Agar, K., \& Baylis, G. C. (1989). Reversing priming while maintaining interference. Bulletin of the Psychonomic Society, 27 , 553-555.

BeEch, A., Baylis, G. C., Smithson, P., \& Claridge, G. S. (1989). Individual differences in schizotypy as reflected in cognitive measures of inhibition. British Journal of Clinical Psychology, 28, 117129.

BEECH, A., \& ClaRidge, G. S. (1987). Individual differences in negative priming: Relations with schizotypal personality traits. British Journal of Psychology, 78, 349-356.

Befch, A., McManus, D., Baylis, G. C., Tipper, S. P., \& Agar, K. (1991). Individual differences in cognitive processes: Towards an explanation of schizophrenic symptomatology. British Journal of Psychology, 82, 417-426.

Beech, A., Powell, T., McWilliam, J., \& Claridge, G. (1989). Evidence of reduced "cognitive inhibition" in schizophrenia. British Journal of Clinical Psychology, 28, 110-116.

Broadbent, D. E., Cooper, P. F., Fitzgerald, P., \& Parkes, K. R. (1982). The cognitive failures questionnaire (CFQ) and its correlates. British Journal of Clinical Psychology, 21, 1-16.

Broadbent, D. E., \& Gathercole, S. E. (1990). The processing of non-target words: Semantic or not? Quarterly Journal of Experimental Psychology, 42A, 3-37.

Chelazzi, L., Miller, E. K., Duncan, J., \& Desimone, R. (1993), A neural basis for visual search in inferior temporal cortex. Nature, $363,345-347$.

ChIAPPE, D. L., \& MaCLeod, C. M. (in press). Negative priming is not task bound: A consistent pattern across naming and categorization tasks. Psychonomic Bulletin \& Review.

Collins, A. M., \& LofTus, E. F. (1975). A spreading activation theory of semantic processing. Psychological Review, 85, 407-428.

CONNELLY, S. L., \& HASHER, L. (1993). Aging and the inhibition of spatial location. Journal of Experimental Psychology: Human Perception \& Performance, 19, 1238-1250.

DAGENBACH, D., \& CARR, T. H. (1994). Inhibitory processes in attention, memory, and language. San Diego: Academic Press.

Dalrymple-Alford, E. C., \& Budayr, B. (1966). Examination of some aspects of the Stroop color-word test. Perceptual \& Motor Skills, 23, 1211-1214.

DESCHEPPER, B. G., \& TREISMAN, A. M. (1991, November). Novel visual shapes in negative priming. Paper presented at the 32nd annual meeting of the Psychonomic Society, San Francisco.

DeutsCh, J. A., \& Deutsch, D. (1963). Attention: Some theoretical considerations. Psychological Review, 70, 80-90.

di PACE, E., Longoni, A. M., \& ZoccolotTI, P. (1991). Semantic processing of unattended parafoveal words. Acta Psychologica, 77, 21-34.

DRIVER, J., \& BAYLIS, G. C. (1993). Cross-modal negative priming and interference in selective attention. Bulletin of the Psychonomic Society, 31, 45-48.

DRIVER, J., \& TIPPER, S. P. (1989). On the nonselectivity of selective seeing: Contrasts between interference and priming in selective attention. Journal of Experimental Psychology: Human Perception \& Performance, 15, 304-414.

DUNCAN, J. (1980). The locus of interference in the perception of simultaneous stimuli. Psychological Review, 87, 272-300.

DUNCAN, J., \& HumphreYs, G. W. (1989). Visual search and stimulus similarity. Psychological Review, 96, 433-458.

DYER, F. N. (1971). The duration of word meaning responses: Stroop interference for different preexposures of the word. Psychonomic Science, 25, 229-231.

Engle, R. W., Conway, A. R. A., Tuholski, S. W., \& Shisler, R. J. (in press). A resource account of inhibition. Psychological Science.

ENRIGHT, S. J., \& BEECH, A. R. (1990). Obsessional states: Anxiety disorders or schizotypes? An information processing and personality assessment. Psychological Medicine, 20, 621-627.

EnRight, S. J., \& BeECh, A. R. (1993a). Further evidence of reduced cognitive inhibition in obsessive-compulsive disorder. Personality \& Individual Differences, 14, 387-395.

ENRJGHT, S. J., \& BEECH, A. R. (1993b). Reduced cognitive inhibition in obsessive-compulsive disorder. British Journal of Clinical Psychology, 32, 67-74.

Eriksen, B. A., \& ErIKsen, C. W. (1974). Effects of noise letters upon the identification of a target letter in a nonsearch task. Perception \& Psychophysics, 16, 143-149.

ERIKSEN, C. W., \& Schultz, D. W. (1979). Information processing in visual search: A continuous flow conception and experimental results. Perception \& Psychophysics, 25, 249-263.

Felleman, D. J., \& VAN ESSEN, D. C. (1991). Distributed hierarchical processing in the primate cerebral cortex. Cerebral Cortex, 1, 1-47.

Fox, E. (1992). Stimulus-response compatibility as a determinant of interference in a Stroop-like task. Bulletin of the Psychonomic Society, 30, 377-380.

Fox, E. (1994a). Attentional bias in anxiety: A defective inhibition hypothesis. Cognition \& Emotion, 8, 165-195.

Fox, E. (1994b). Interference and negative priming from ignored distractors: The role of selection difficulty. Perception \& Psychophysics, 56, 565-574.

Fox, E. (1995). Pre-cueing target location reduces interference but not negative priming from visual distractors. Quarterly Journal of Experimental Psychology, 48A, 26-40.

FRANCOLINI, C. M., \& EGETH, H. E. (1980). On the nonautomaticity of "automatic" activation: Evidence of selective seeing. Perception \& Psychophysics, 27, 331-342.

FRITH, C. D. (1979). Consciousness, information processing, and schizophrenia. British Journal of Psychiatry, 134, 225-235.

Fuentes, L. J., Carmona, E., Agis, I. F., \& Catena, A. (1994). The 
role of the anterior attention system in semantic processing of both foveal and parafoveal words. Journal of Cognitive Neuroscience, $\mathbf{6}$, 17-25.

Fuentes, L. J., \& Tudela, P. (1992). Semantic processing of foveally and parafoveally presented words in a lexical decision task. Quarterly Journal of Experimental Psychology, 45A, 299-322.

Gathercole, S. E., \& Broadbent, D. E. (1987). Spatial factors in visual attention: Some compensatory effects of location and time of arrival of nontargets. Perception, 16, 433-443.

GATTI, S. V., \& EGETH, H. E. (1978). Failure of spatial selectivity in vision. Bulletin of the Psychonomic Saciety, 11, 181-184.

Gernsbacher, M. A., \& FAuST, M. E. (1991). The mechanism of suppression: A component of general comprehension skill. Journal of Experimental Psychology: Learning, Memory, \& Cognition, 17, 245-262.

Hasher, L., Stoltzfus, E. R, Zacks, R. T., \& Rympa, B. (1991). Age and inhibition. Journal of Experimental Psychology: Learning, Memory, \& Cognition, 17, 163-169.

HASHER, L., \& ZACKS, R. L. (1988). Working memory, comprehension, and aging: A review and a new view. In G. H. Bower (Ed.), The psychology of learning and motivation (Vol. 22, pp. 193-225). New York: Academic Press.

HOLENDER, D. (1986). Semantic activation without conscious identification in dichotic listening, parafoveal vision, and visual masking: A survey and appraisal. Behavioral \& Brain Sciences, 9, 1-66.

Hovghton, G., \& TrPPER, S. P. (1994). A model of inhibitory mechanisms in selective attention. In D. Dagenbach \& T. Carr (Eds.), Inhibitory mechanisms in attention, memory and language (pp. 53112). San Diego, CA: Academic Press.

Johnston, J. A., \& DARK, V. J. (1986). Selective attention. Annual Review of Psychology, 37, 43-75.

Kahneman, D., \& Treisman, A. M. (1984). Changing views of attention and automaticity. In R. Parasuraman \& P. R. Davies (Eds.), Varieties of attention (pp. 29-61). New York: Academic Press

KeELE, S. W., \& NeILL, W. T. (1978). Mechanisms of attention. In E. C. Carterette \& M. P. Friedman (Eds.), Handbook of perception (Vol. 9, pp. 3-47). San Diego, CA: Academic Press.

LAMBERT, A. J. (1985). Selectivity and stages of processing-an enduring controversy in attentional theory: A review. Current Psychological Research \& Reviews, 4, 239-256.

Lambert, A. J., Beard, C. T., \& THOMPSON, R. J. (1988). Selective attention, visual laterality, awareness, and perceiving the meaning of parafoveally presented words. Quarterly Journal of Experimental Psychology, 40A, 615-652.

LAVIE, N. (in press). Perceptual load as a necessary condition for selective attention. Journal of Experimental Psychology: Human Perception \& Performance.

Lavie, N., \& Tsal, Y. (1994). Perceptual load as a major determinant of the locus of selection in visual attention. Perception \& Psychophysics, 56, 183-197.

LOGAN, G. D. (1988). Toward an instance theory of automatization. Psychological Review, 95, 492-527.

LoGAN, G. D. (1990). Repetition priming and automaticity: Common underlying mechanisms? Cognitive Psychology, 22, 1-35.

LOWE, D. G. (1979). Strategies, context, and the mechanism of response inhibition. Memary \& Cognition, 7, 382-389.

LOWE, D. G. (1985). Further investigations of inhibitory mechanisms in attention. Memory \& Cognition, 13, 74-80.

MACLEOD, C. M. (1991). Half a century of research on the Stroop effect: An integrative review. Psychological Bulletin, 109, 163-203.

MALley, G. B., \& STRAYER, D. L. (in press). Effect of stimulus repetition on positive and negative identity priming. Perception \& Psychophysics.

May, C. P., Kane, M. J., \& Hasher, L. (in press). Determinants of negative priming. Psychological Bulletin.

MCCLAiN, L. (1983). Stimulus-response compatibility affects auditory Stroop interference. Perception \& Psychophysics, 33, 266-270.

MCDowd, J. M., \& Oseas-Kreger, D. M. (1991). Aging, inhibitory processes, and negative priming. Journal of Gerontology: Psychological Sciences, 46, 340-345.

MILLER, J. (1991). The flanker compatibility effect as a function of visual angle, attentional focus, visual transients, and perceptual load:
A search for boundary conditions. Perception \& Psychophysics, 49, 270-288.

Milliken, B., Tipper, S. P., \& Weaver, B. (1994), Negative priming in a spatial localization task: Feature mismatching and inhibition of distractor location. Journal of Experimental Psychology: Human Perception \& Performance, 20, 624-646.

Moore, C. M. (1994). Negative priming depends on probe-trial conflict: Where has all the inhibition gone? Perception \& Psychophysics, 56, 133-147.

MORAN, J., \& Desimone, R. (1985, August). Selective attention gates visual processing in the extrastriate cortex. Science, 229, 782-784.

NeILL, W. T. (1977). Inhibitory and facilitatory processes in selective attention. Journal of Experimental Psychology: Human Perception \& Performance, 3, 444-450.

NeILL, W. T. (1979). Switching attention within and between categories: Evidence for intracategory inhibition. Memory \& Cognition, 7, 283-290.

NeILL, W. T. (1989). Lexical ambiguity and context: An activationsuppression model. In D. S. Gorfein (Ed.), Resolving semantic ambiguity (pp. 63-83). New York: Springer-Verlag.

NeILl, W. T. (1991, August). Consciousness and the inhibitory control of cognition. Invited address at the annual meeting of the American Psychological Association, San Francisco.

NeILL, W. T., \& Lissner, L. S. (1988). Attention and selective inhibition in alphanumeric matching. Paper presented at the annual meeting of the Eastern Psychological Association, Buffalo, NY.

NeILL, W. T., LISSNER, L. S., \& BECK, J. L. (1990). Negative priming in same-different matching: Further evidence for a central locus of inhibition. Perception \& Psychophysics, 48, 398-400.

NeILL, W. T., TERRY, K. M., \& VALDES, L. A. (1994). Negative priming without probe selection. Psychonomic Bulletin \& Review, 1, 119121.

NeILl, W. T., \& VALDES, L. A. (1992). Persistence of negative priming: Steady state or decay? Journal of Experimental Psychology: Learning, Memory, \& Cognition, 18, 565-576.

Neill, W. T., VAldes, L. A., \& TerRY, K. M. (1992, November). Negative priming in target localization. Paper presented at the 33rd annual meeting of the Psychonomic Society, St. Louis.

Neill, W. T., Valdes, L. A., \& Terry, K. M. (in press). Selective attention and the inhibitory control of cognition. In F. N. Dempster \& C. J. Brainerd (Eds.), New perspectives on interference and inhibition in cognition. New York: Academic Press.

Neill, W. T., Valdes, L. A., Terry, K. M., \& Gorfein, D. S. (1992). Persistence of negative priming: II. Evidence for episodic trace retrieval. Journal of Experimental Psychology: Learning, Memory, \& Cognition, 18, 993-1000.

NeILL, W. T., \& WESTBERRY, R. L. (1987). Selective attention and the suppression of cognitive noise. Journal of Experimental Psychology: Learning, Memory, \& Cognition, 13, 327-334.

Neumann, E., Cherau, J. F., Hood, K. L., \& Steinnagel, S. L. (1993). Does inhibition spread in a manner analogous to spreading activation? Memory, 1, 81-105.

Neumann, E., \& DeSchepper, B. G. (1991). Costs and benefits of target activation and distractor inhibition in selective attention. Journal of Experimental Psychology: Learning, Memory, \& Cognition, 17, 1136-1145.

Neumann, E., \& DeSchepper, B. G. (1992). An inhibition-based fan effect: Evidence for an active suppression mechanism in selective attention. Canadian Journal of Psychology, 46, 1-40.

Newell, A. (1990). Unified theories of cognition. Cambridge, MA: Harvard University Press.

Paquet, L., \& LorTie, C. (1990). Evidence for early selection: Precuing target location reduces interference from same-category distractors. Perception \& Psychophysics, 48, 382-388.

PARK, J., \& KANWISHER, N. (1994). Negative priming for spatial locations: Identity mismatching, not distractor inhibition. Journal of Experimental Psychology: Human Perception \& Performance, 20, 613-623.

PosNer, M. I., \& DRIVER, J. (1992). The neurobiology of selective attention. Current Opinion in Neurobiology, 2, 165-169.

RUECKL, R. G., CAVE, K. R., \& KossLYN, S. M. (1989). Why are "what" and "where" processed by separate cortical visual systems? A com- 
putational investigation. Journal of Cognitive Neuroscience, 1, 171 . 186.

Scarborough, D. L., Cortese, C., \& Scarborough, H. S. (1977). Frequency and repetition effects in lexical memory. Journal of Experimental Psychology: Human Perception \& Performance, 3, 1-17.

ShafFer, W .O., \& LABERGE, D. (1979). Automatic semantic processing of unattended words. Journal of Verbal Learning \& Verbal Behavior, 18, 413-426.

STROOP, J. R. (1935). Studies of interference in serial verbal reactions. Journal of Experimental Psychology, 18, 643-662.

TIPPER, S. P. (1985). The negative priming effect: Inhibitory priming by ignored objects. Quarterly Journal of Experimental Psychology, 37A, 571-590.

TIPPER, S. P. (1991). Less attentional selectivity as a result of declining inhibition in older adults. Bulletin of the Psychonomic Society, 29, 45-47.

TIPPER, S. P., \& BAYLIS, G. C. (1987). Individual differences in selective attention: The relation of priming and interference to cognitive failure. Personality \& Individual Differences, 8, 667-675.

TipPer, S. P., Borque, T. A., ANDERSon, S. H., \& Brehaut, J. (1989) Mechanisms of attention: A developmental study. Journal of Experimental Child Psychology, 48, 353-378.

Tipper, S. P., Brehaut, J. C., \& Driver, J. (1990). Selection of moving and static objects for the control of spatially directed action. Journal of Experimental Psychology: Human Perception \& Performance, 16, 492-504.

TIPPER, S. P., \& Cranston, M. (1985). Selective attention and priming Inhibitory and facilitatory effects of ignored primes. Quarterly Journal of Experimental Psychology, 37A, 591-611.

TIPPER, S. P., \& DRIVER, J. (1988). Negative priming between pictures and words in a selective attention task: Evidence for semantic processing of ignored stimuli. Memory \& Cognition, 16, 64-70.

TIPPER, S. P., LORTIE, C., \& BAYLIS, G. C. (1992). Selective reaching: Evidence for action-centered attention. Journal of Experimental Psychology: Human Perception \& Performance, 18, 891-905.

TipPeR, S. P., MacQueEn, G. M., \& Brehaut, J. C. (1988). Negative priming between response modalities: Evidence for the central locus of inhibition in selective attention. Perception \& Psychophysics, 43, 45-52.

TIPPER, S. P., \& MCLAREN, J. (1990). Evidence for efficient selectivity in children. In J. T. Enns (Ed.), The development of attention: Research and theory (pp. 197-210). Amsterdam: North-Holland.

Tipper, S. P., Weaver, B., Cameron, S., Brehaut, J., \& Bastedo, J. (1991). Inhibitory mechanisms of attention in identification and localization tasks: Time course and disruption. Journal of Experimental Psychology: Learning, Memory, \& Cognition, 17, 681-692.

TipPER, S. P., Weaver, B., \& Houghton, G. (1994). Behavioural goals determine inhibitory mechanisms of selective attention. Quarterly Journal of Experimental Psychology, 47A, 809-840.

TipPer, S. P., Weaver, B., KirkPatrick, J., \& Lewis, S. (1991). Inhibitory mechanisms of attention: Locus, stability, and relationship with distractor interference effects. British Journal of Psychology, $82,507-520$.

Treisman, A. M. (1969). Strategies and models of selective attention. Psychological Review, 76, 282-299.

Treisman, A. M. (1992). Perceiving and re-perceiving objects. American Psychologist, 47, 862-875.

Tulving, E., \& THOMPson, D. M. (1973). Encoding specificity and retrieval processes in episodic memory. Psychological Review, 80, 1-52.

UNDERWOOD, G. (1981). Lexical recognition of embedded unattended words: Some implications for reading processes. Acta Psychologica, 47, 267-283.

Underwood, G., Rusted, J., \& Thwaites, S. (1983). Parafoveal words are effective in both hemifields: Preattentive processing of semantic and phonological codes. Perception, 12, 213-221.
Underwood, G., \& Thwaites, S. (1982). Automatic phonological coding of unattended printed words. Memory \& Cognition, 10, 434442 .

UNGERLEIDER, L. G., \& MishKin, M. (1982). Two cortical visual systems. In D. J. Ingle., M. A. Goodale., \& R. W. J. Mansfield (Eds.), Analysis of visual behavior (pp. 549-586). Cambridge, MA: MIT Press.

VALDES, L. A. (1993). The relation of negative priming to interference. Unpublished doctoral dissertation, Adelphi University, Garden City, NY.

VAN DER HeIJDEN, A. H. C. (1992). Selective attention in vision. London: Routledge \& Kegan Paul.

WhITE, M. J. (in press). Unattended words need to be primed to be recognized. Canadian Journal of Experimental Psychology.

YEE, P. L. (1991). Semantic inhibition of ignored words during a figure classification task. Quarterly Journal of Experimental Psychology, 43A, 127-153.

\section{NOTES}

1. I became aware of another review of the NP literature (May, Kane, \& Hasher, in press) after the final version of the present manuscript was completed. Points at which the two reviews come to similar and/or dissimilar conclusions are noted in the text.

2. It is quite possible that ignored stimuli are processed by means of some early-selection mechanism, such as repetition or schematic priming (Johnston \& Dark, 1986). Alternatively, it is possible that ignored stimuli are processed at some point after target selection (Gathercole \& Broadbent, 1987). As Driver and Tipper (1989) point out, this is very different from the original early-selection assertion that distractors are completely filtered out: It is now claimed that they are not totally excluded from semantic processing but, rather, that processing is delayed relative to processing of target material. Thus, NP cannot be taken as conclusive evidence either that selection of relevant objects occurs early in information processing or that it occurs late in information processing. What it does indicate is that processing of ignored stimuli (at whatever point) appears to be unavoidable in many visualselection tasks.

3. It should be noted that even though NP was not dependent on an identity switch between the prime-target and probe-target locations, there was always a mismatch between the identities appearing in the prime-distractor location (e.g., $G$ ) and the probe-target location (e.g., $B$ ), so feature mismatching may still have caused the NP effect.

4. This result is in contrast to other research (with letter stimuli) which shows that the magnitude of NP decreases as the number of distractors increases (Neumann et al., 1993; Neumann and DeSchepper, 1992).

5. It should be noted that this assumption might depend on the heterogeneity of the distractors (see Duncan \& Humphreys, 1989).

6. It is interesting to note that the recent perceptual load hypothesis put forward by Lavie and Tsal (1994) would make directly the opposite prediction. Lavie and Tsal argue that perceptual load is a major determinant of the locus of selective attention. When perceptual load is very low, late selection is observed, whereas early selection is observed when perceptual load is high (see Lavie, in press, for relevant data). If this view is correct, when task processing is very demanding, a decrease in NP would be predicted, rather than an increase, as suggested by Moore (1994). Results consistent with the perceptual load hypothesis have recently been reported by Engle, Conway, Tuholski, and Shisler (in press). In a letter-naming task, they found that NP was diminished as memory load increased.

(Manuscript received June 2, 1993; revision accepted for publication on January 17,1995 .) 